Progress Report to the UNITED STATES DEPARTMENT OF ENERGY

For the Period September 1, 1990 to August 31, 1991

The Third Year of a Three-Year Research Program on

\title{
High-Power Microwave Transmission Systems for Electron-Cyclotron-Resonance Plasma Heating
}

by

Professor Ronald J. Vernon

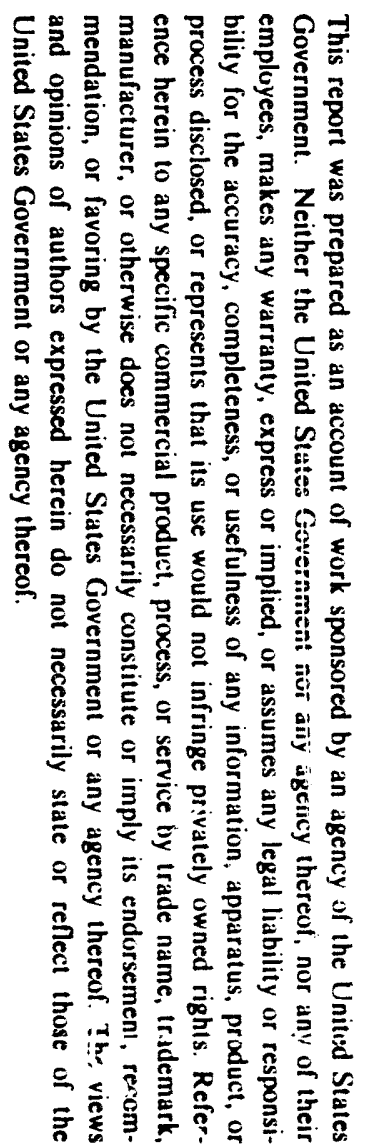

Principal Investigator

Department of Electrical and Computer Engineering,

The University of Wisconsin System

$\frac{8}{8}$

Madison, Wisconsin 53706

August 1991

\section{MASTER}

XWP 


\title{
High-Power Microwave Transmission Systems \\ for Electron-Cyclotron-Resonance Plasma Heating
}

\author{
R. J. Vernon \\ $5: 56165$ \\ Principal Investigator \\ Department of Electrical and Computer Engineering \\ University of Wisconsin-Madison \\ Madison, Wisconsin 53706
}

\begin{abstract}
This progress report is for the sixth year of a grant from the U.S. Department of Energy (Contract DE-FG02-85ER52122) for the design, development, and fabrication of ECRH transmission and mode conversion systems to transport microwave power from a gyrotron to a magnetically confined plasma. (This period is also the third year covered by a three-year renewal proposal submitted in June of 1988.) The design and low-power testing of new and improved components for such systems and development of underlying theory is the focus of this project. Devising and improving component testing and diagnostic techniques is also an important part of this effort. The development of possible designs for sections of gyrotrons themselves, such as tapers or Vlasov-type launchers, in support of the Varian gyrotron development program is also considered when appropriate. We also provide support to other groups working on ECR heating of magnetically confined plasmas such as the groups at General Atomics, the University of Texas at Austin, and Lawrence Livermore National Laboratory.
\end{abstract}

During the last year, we designed and had fabricated a two-dimensional Vlasov antenna system for a $110 \mathrm{GHz}^{\mathrm{T}} \mathrm{TE}_{15,2}$ mode gyrotron for possible use at General Atomics. The system included the launcher section, a visor, main 
reflector, and focussing reflector. Programs to generate the tool-path profiles to cut the "General Atomics" Vlasov components on a milling machine were developed. We have also developed state-of-the-art theory and programs for threedimensional whispering-gallery-mode Vlasov antenna systems (launcher, subreflector, and main reflector) from geometrical optics principals. We made improvements on models for the radiation patterns from $\mathrm{TE}_{0 \mathrm{n}}$ mode Vlasov launchers which were compared to measured patterns. Similar models were developed for whispering-gallery-mode Vlasov launchers. Measurements will be made of Vlasov launcher radiation patterns in the next fiscal year.

A design for a $110 \mathrm{GHz} \mathrm{TE}_{01}-\mathrm{TE}_{15,2}$ mode-converter system for cold testing WGM Vlasov antenna systems was developed and is currently being fabricated. A $60 \mathrm{GHz}$ azimuthal-aperture-array WG-mode generator was designed and fabricated for the $\mathrm{TE}_{6 \mathrm{n}}$ modes. It was tested by the radiation pattern measurement method and found to produce $\mathrm{TE}_{62}$ and $\mathrm{TE}_{61}$ modes of adequate purity. Further improvements will be made on this device. Mode coupling due to ohmic wall losses alone was investigated and found not to be a serious problem in most common mode converters. 


\section{TABLE OF CONTENTS}

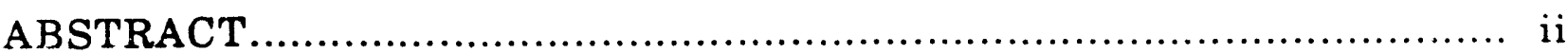

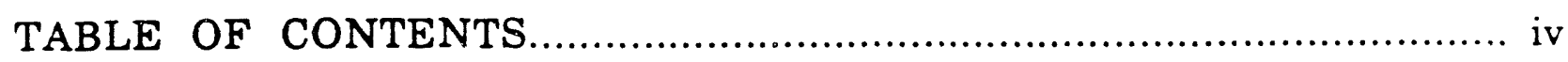

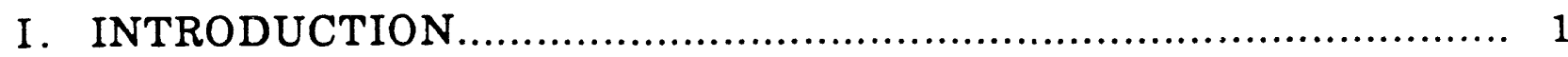

II. CURRENT RESEARCH AND RESEARCH PERFORMED OVER THE PAST

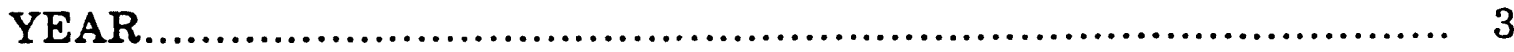

II-A. Vlasov Launcher Development.............................................. 3

II-A-1. Whispering-Gallery-Mode Vlasov Launchers............................. 3

II-A-2. TE $\mathrm{TE}_{\mathrm{n}}$ Mode Vlasov Launchers................................................ 5

II-B. Whispering-Gallery Mode Generator Development....................... 7

II-B-1. Generation of Low-Power Whispering-Gallery Modes with PerturbedWall Waveguide Mode Converters................................................. 8

II-B-2. Generation of Low-Power Whispering-Gallery Modes with Azimuthal Aperture Arrays............................................................ 9

II-C. Mode Converter Development..................................................... 11

II-D. Taper Designs.............................................................. 12

II-E. Other Activities.............................................................. 12

II-E-1. Attenuation and Phase Constant Near Cutoff and Mode Coupling Due to Wall Losses..................................................................... 12

II-E-2. Phase Pattern Measurement............................................. 13

II-E-3. Radiation Pattern Measurement Facility Improvement................... 13

II-F. Special Activities........................................................... 14

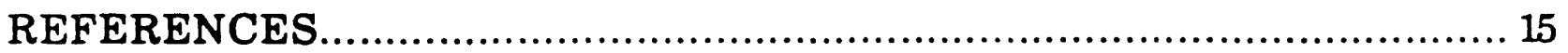

PUBLICATIONS RESULTING FROM PROJECT RESEARCH....................... 16

GRADUATE STUDENTS ASSOCIATED WITH PAST AND PRESENT

CONTRACT RESEARCH EFFORT.................................................... 20

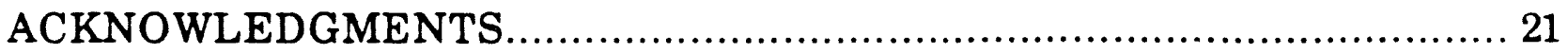




\section{INTRODUCTION}

This progress report is for the sixth year of a grant from the U.S. Department of Energy (Contract DE-FG02-85ER52122) for the design, development, and fabrication of ECRH transmission and mode conversion systems to transport microwave power from a gyrotron to a magnetically confined plasma. (This period is also the third year covered by a three-year renewal proposal submitted in June of 1988.) The design and low-power testing of new and improved components for such systems and development of underlying theory is the focus of this project. Devising and improving component testing and diagnostic techniques is also an important part of this effort. The development of possible designs for sections of gyrotrons themselves, such as tapers or Vlasov-type launchers, in support of the Varian gyrotron development program is also considered when appropriate. We also provide support to other groups working on ECR heating of magnetically confined plasmas such as the groups at General Atomics, the University of Texas at Austin, and Lawrence Livermore National Laboratory.

During the last year, we have designed a two-dimensional whisperinggallery-mode Vlasov antenna system which uses an extension to the helical cut sometimes called a visor. This system was designed for possible use as a backup system for the $110 \mathrm{GHz}$ gyrotrons to be used by General Atomics. Machine drawings for these components were made and the parts were fabricated on a numerically controlled milling machine. We have also completed the theory for a three dimensional Vlasov antenna system and the computer code for the system design is nearly complete.

We have developed more accurate models for the radiation from $\mathrm{TE}_{0 \mathrm{n}}$ mode Vlasov launcher baffles of both the step-cut and slant-cut variety. This model gives good agreement with measured radiation patterns for $\mathrm{TE}_{01}$ modes for the main lobe and two secondary lobes. We will apply a similar model to the more difficult whispering-gallery modes during the next year and compare these results with theory.

In the past, this project has emphasized the development of theory, design, fabrication, and testing of waveguide mode converters and tapers. During the last 
fiscal year, our mode converter and taper design work has principally been involved with the development of mode converters and tapers for high-power 110 and $140 \mathrm{GHz}$ gyrotrons. In particular, we have developed an improved design for a mode converter system to transform the $\mathrm{TE}_{01}$ mode in a circular waveguide to the rotating $\mathrm{TE}_{15,2}$ mode to be used for tesing our Vlasov antenna designs at low power.

Over the last several years, we have also developed diagnostic techniques and capabilities to evaluate mode converter performance, particularly methods of mode content determination by open-end radiation pattern analysis and $\mathrm{k}$ spectrometer measurement. During the last year, we have continued work on these methods at a background level impriving the computer program for data acquisition and manipulation that was begun the previous year and developing the capability to make phase pattern measurements. We have also added the capacity to take azimuthal radiation pattern measurements in our anechoic chamber.

Over the next year, we propose to expand our work on Vlasov launchers and to continue our development effort on mode converters and tapers for whisperinggallery mode (WGM) type gyrotrons. We will also continue our effort in improving mode content determination by the open-end radiation pattern method and $k$-spectrometer measurements. We will continue the work on upgrading our radiation pattern measurement facility to improve our capacity for the measurement of phase patterns which will become important in Vlasov reflector design and will be useful in mode-content determination measurements. We will also develop a $110 \mathrm{GHz}$ low-power radiation pattern measurement facility. 


\section{CURRENT RESEARCH AND \\ RESEARCH PERFORMED OVER THE PAST YEAR}

\section{II-A. Vlasov Antenna Development}

\section{II-A-1. Whispering-Gallery-Mode Vlasov Antennas}

The latest generation high-power high-frequency gyrotrons currently under development at Varian and proposed for future development operate with rotating cavity modes having a high azimuthal mode index. These modes are often called whispering-gallery modes (WG modes or WGM). A device called a Vlasov antenna [1], shown in simple form in Fig. 1, can be used with such modes to obtain an approximately linearly polarized beam output. This beam can then be focused into a circular waveguide or transmitted by quasi-optical techniques.

Early Vlasov antenna designs were essentially a circulár waveguide terminated by a helical cut radiating into a parabolic-cylinder reflector as shown in Fig. 1. The radiation pattern of these early devices exhibited appreciable sidelobe structure and only fair polarization properties. Less than $70 \%$ of the gyrotron output power was in the main beam. Later refinements have improved these characteristics.

We have developed theory based on ray optics methods for a two-dimensional Vlasov launcher system which uses an extension to the helical cut, sometimes called a visor, which is shown in cross-sectional form in Fig. 2. This second reflecting surface allows one to obtain an arbitrary power distribution across the transverse dimension of the outrut beam. Beginning with the expressions for the fields of the whispering-gallery mode, we have developed in a rigorous and selfconsistent manner a desi/gn procedure for a two-dimensional Vlasov antenna system which converts arı arbitrary WG mode or similar input to an arbitrary desired power distributicin across the transverse dimension of the output beam. The desired output would normally be a beam with a Gaussian distribution in the transverse direction. The visor and the secondary reflector profiles become solutions to a system of coupled differential equations. A somewhat simplified version of the theory and associated computer code which we have written was used last year to verify a design being used on the Microwave Tokamak 


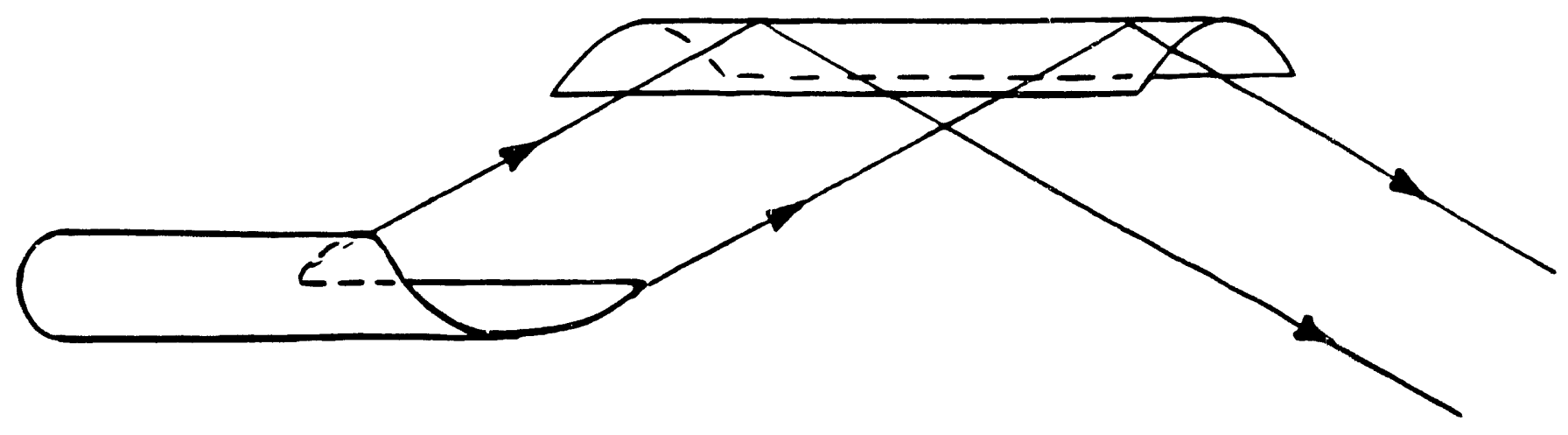

Fig. 1. Schematic drawing of a simple Vlasov launcher for a rotating whisperinggallery-type mode showing the spiral waveguide end and the parabolic reflector. 


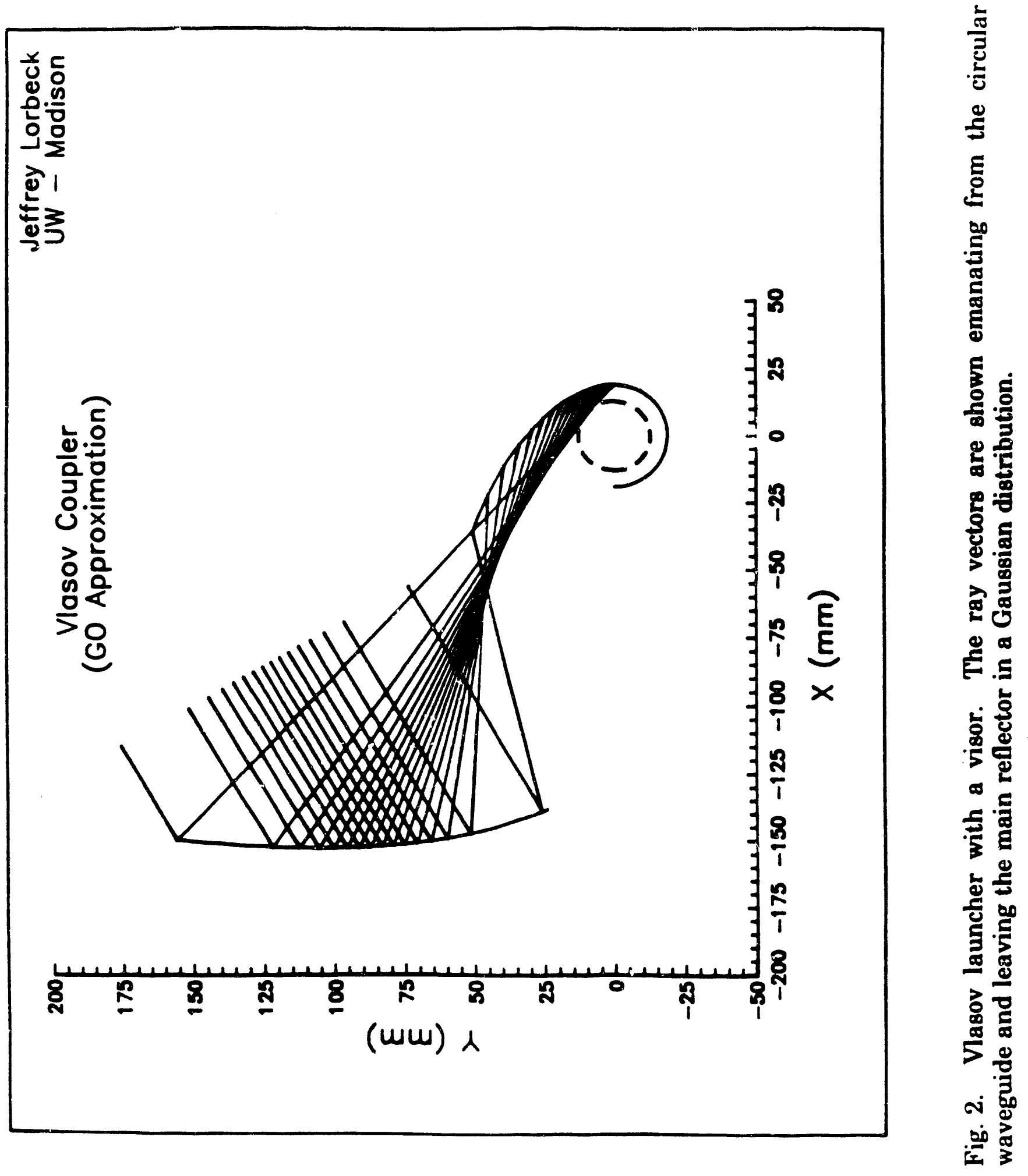


- Experiment (MTX) at the Lawrence Livermore National Laboratory. The gyrotron there operates at $140 \mathrm{GHz}$ in the $\mathrm{TE}_{15,2}$ mode.

We have used this theory to design a Vlasov antenna system, shown schematically in Fig. 3., for the $\mathrm{TE}_{15,2}$ mode at $110 \mathrm{GHz}$ for possible use by General Atomics as a back up to the innovative system developed by Moeller. The two dimensional system we have designed uses a focusing mirror following the main reflector of the Vlasov antenna to couple the energy into a corrugated waveguide. The shape and orientation of this mirror were chosen to maximize the coupling efficiency from the free-space mode to the $\mathrm{HE}_{11}$ mode of the corrugated waveguide. A complete set of machine drawings for the five parts making up this system was dratued at no expense to General Atomics. Since the components of the system are being machined locally in Madison, we also developed the computer code necessary to provide the machinists with the appropriate tool paths for their milling machine. This system could be tested in our anechoic chamber in Madison as soon as our $110 \mathrm{GHz}^{\mathrm{T}} \mathrm{E}_{15,2}$ mode generating system (see Sec. II-B-1) is operational.

Our first Vlasov launcher design using a visor, while a vast improvement over the earliest Vlasov converters (the Japanese have reported measured conversion efficiencies of $93 \%$ compared with less than $70 \%$ in the initial Vlasov design [1]) is still limited by the two-dimensional nature of the reflecting surfaces. The background theory for a full three-dimensional design has been completed and the necessary computer code is nearly finished. This design technique will allow nearly arbitrary beam power profile shaping and phase distribution that may be tailored for the intended application. Although a theoretical development of three-dimensional dual-reflector systems with arbitrary output amplitude and phase distribution has appeared in the literature, our analysis includes major modifications to this theory which had not previously been applied to Vlasov launcher type systems.

The three-dimensional design theory applied to the Vlasov antenna is quite complex due to the distributed nature of the primary radiator (the helical-cut waveguide aperture). However, we have completed the rather lengthy calculations required to express the generating equations (coupled differential equations) for the reflecting surfaces. The computational algorithms and 


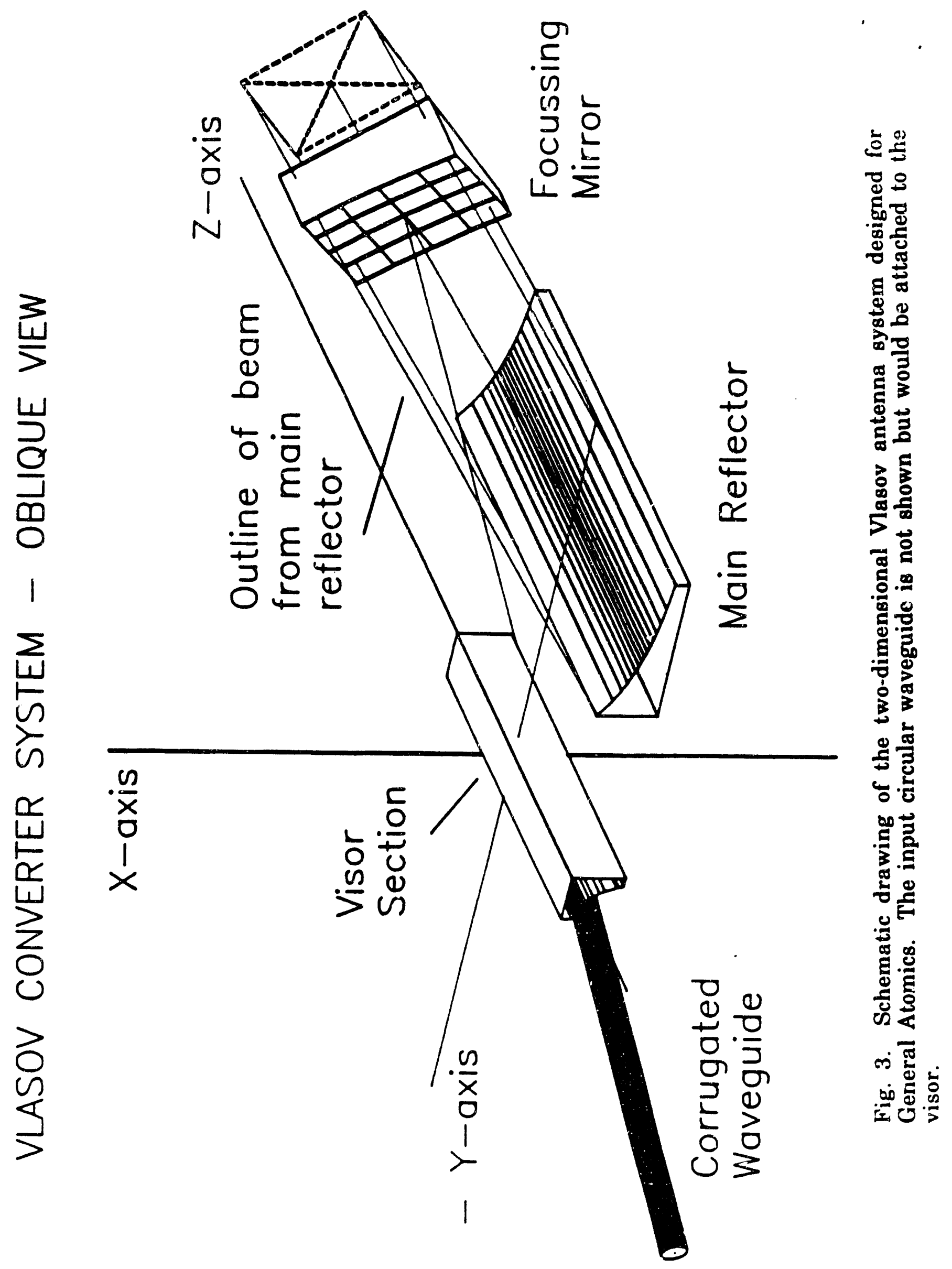


- numerical coding of the theory are quite involved and are being developed to run on the supercomputers available on the NERSC system. Autolisp routines to incorporate synthesized surfaces directly into CAD drawings have also been developed. Figure 4 shows the synthesized reflectors for a preliminary design. Note that both the sub- and main reflectors may be placed in a circular cylinder with a diameter of $30 \mathrm{~cm}$.

A final design will be developed for possible use at either the University of Texas at Austin or General Atomics. Then a design for possible use inside a gyrotron will be developed.

Other issues that will be addressed are the polarization and diffraction properties of the three-dimensional system. During the next year, we will also consider using small distortions (dimples) in the waveguide just preceding the launcher to obtain a narrower radiation pattern from the baffle.

\section{II-A-2. TE 0 Mode Vlasov Launchers}

We are also studying both step-cut and slant-cut $\mathrm{TE}_{0 \mathrm{n}}$ and $\mathrm{TM}_{\mathrm{On}}$ mode Vlasov launchers as shown in Fig. 5. We are studying these launchers for their own importance as well as to develop theory, write computer programs, and gain insights which will be applied to the more important Vlasov launcher for highazimuthal-index rotating modes (whispering-gallery or WG modes) such as the rotating $\mathrm{TE}_{15,2}$ mode. The $\mathrm{TE}_{0 \mathrm{n}}$ mode launchers are somewhat easier to analyze and understand. Also, we have long been able to produce pure $\mathrm{TE}_{0 \mathrm{n}}$ and $\mathrm{TM}_{01}$ modes in our laboratory whereas our capability to produce the more complex WG modes is just being realized this summer. (The development of methods of generating relatively pure WG type modes is also an important part of our present and proposed program as discussed in Sec.II-B-3.) Having pure low-power $\mathrm{TE}_{0 \mathrm{n}}$ modes available in the laboratory has allowed us to compare our analytical and computational results with measured results to test them in a meaningful way. These tools will now be applied to the WGM launchers as the necessary mode generators become available. 

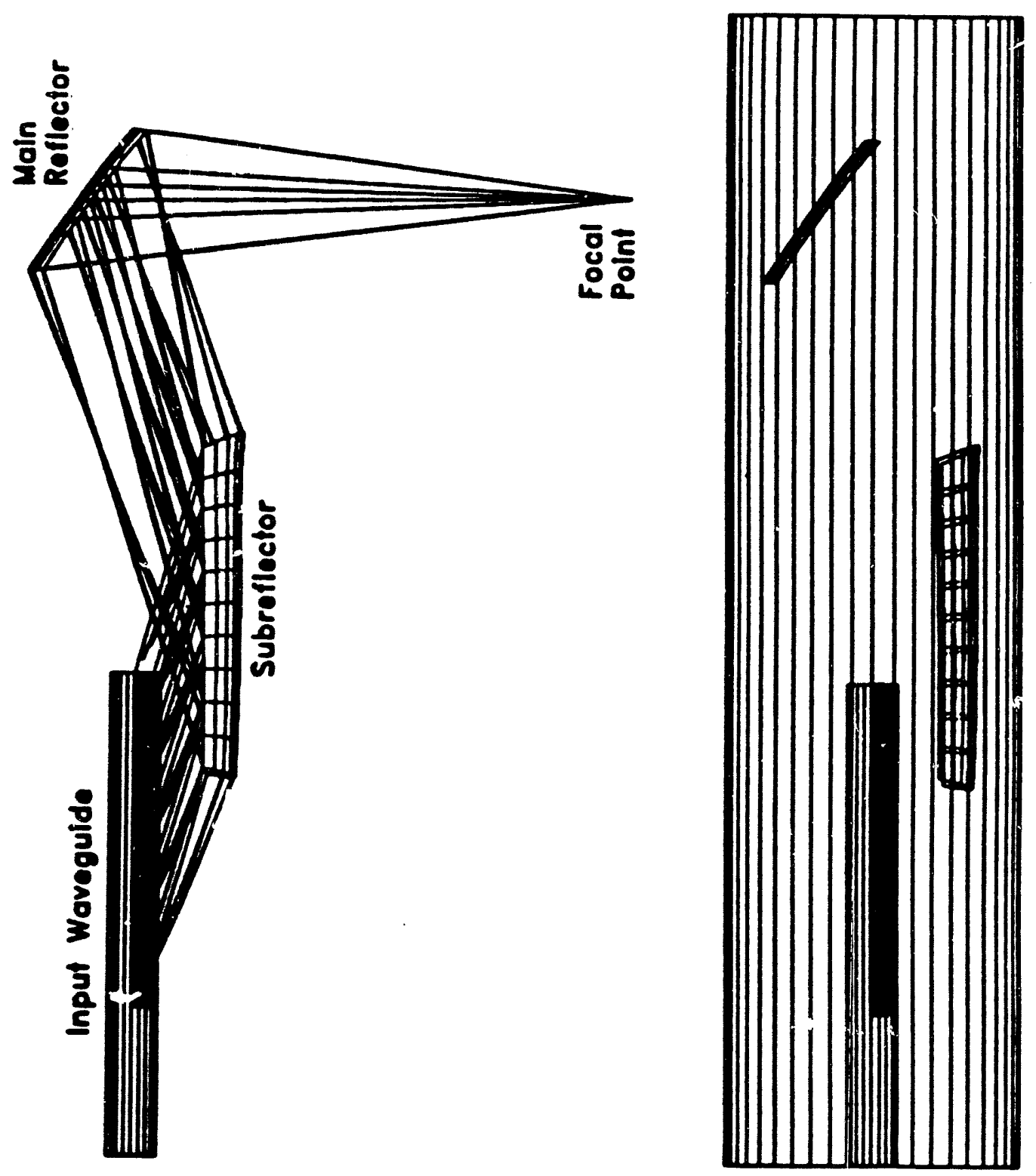

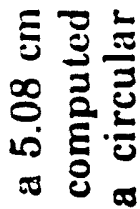

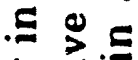

些然

苟

인

造曹

ํํㄹ है

ํㅡㄹ

.

ㄷํ으.

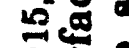

올 点点

옹

s.

E

要

ํㅗㅇ

乌ั

을일

票

웡

을

范

政。

อั

๑灾

+ 要

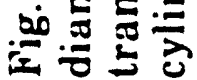




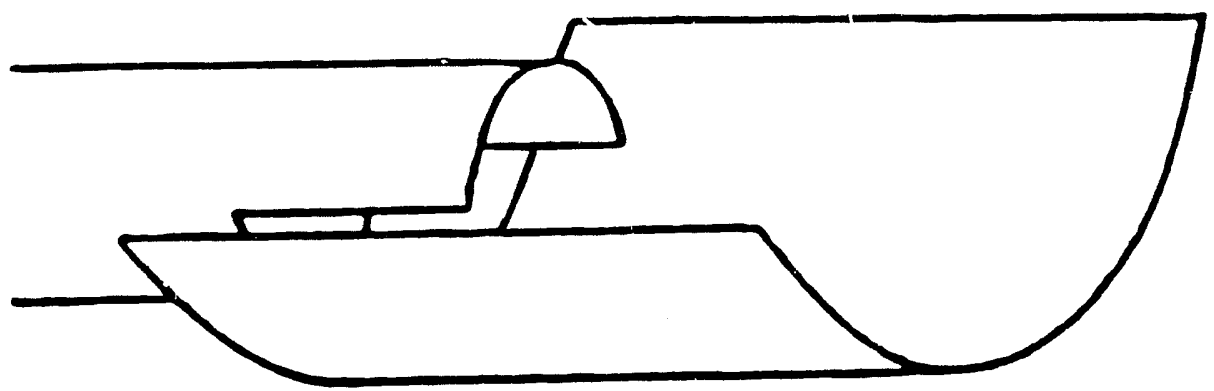

a
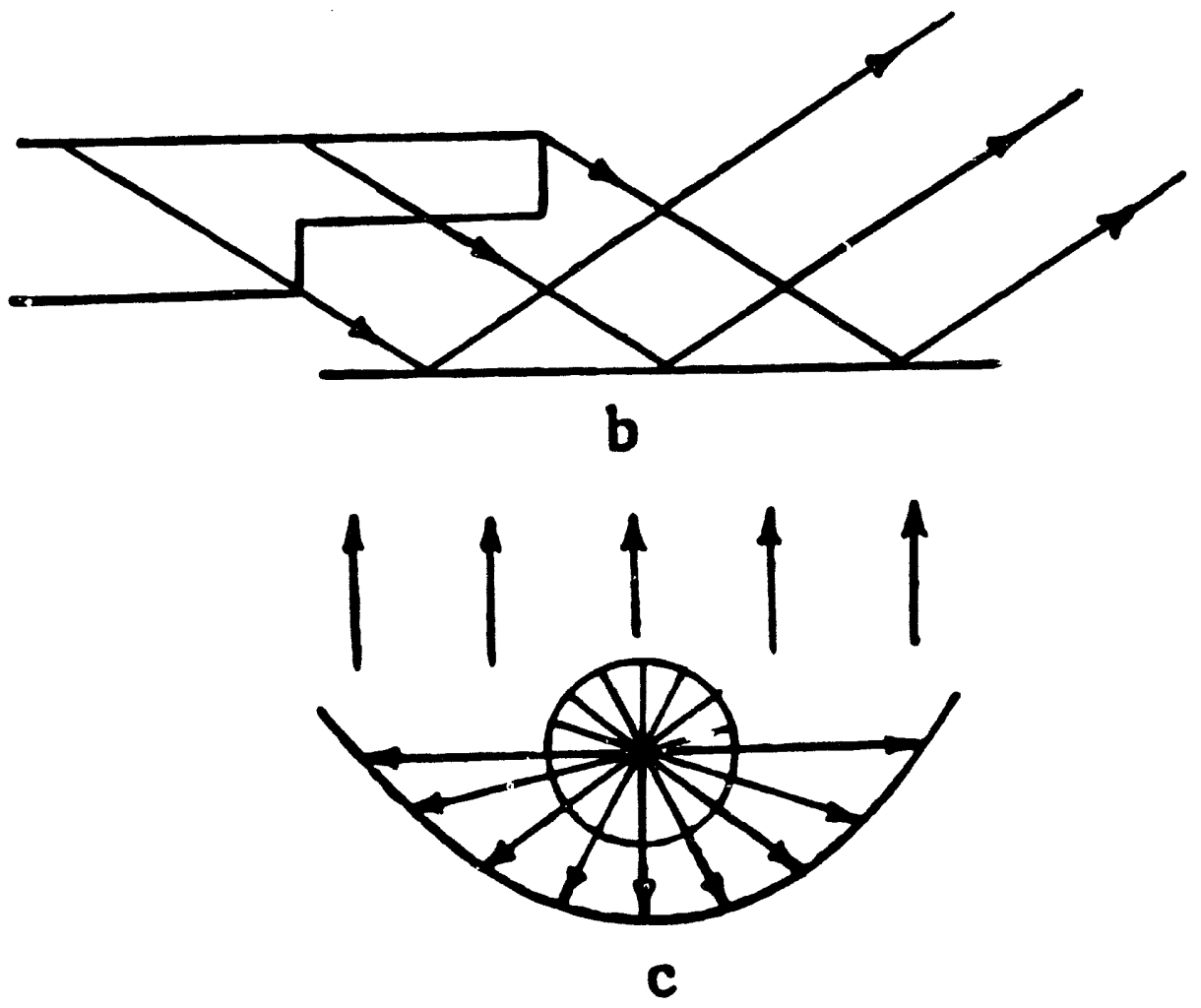

Fig. 5. a) $\mathrm{TE}_{0 \mathrm{n}}$ Vlasov launcher showing the half-cylinder baffle and paraboliccylinder reflector. b) a ad c) Cross-sectional views of a) showing geometrical rays. 
In the past, we have considered several theoretical models for the radiation patterns from $\mathrm{TE}_{0 \mathrm{n}}$ and $\mathrm{TM}_{01}$ mode Vlasov baffles. The most successful to date uses the equivalence principle to obtain equivalent currents over the waveguide aperture and the baffle (the region from $0 \leq z \leq \ell$ and $\pi / 2 \leq \phi \leq 3 \pi / 2$ using the coordinate system of Figs. 5 and 6). Here $\ell$ is the baffle length (one-half the bounce length). The unperturbed waveguide fields were used as a first approximation to these currents. Analytic expressions have been obtained for the radiation in the far field and a computer program has been developed for the fields at smaller distances. We have also made measurements of the radiation patterns from both step-cut and slant-cut baffles in a $2.779 \mathrm{~cm}$ diameter waveguide at $60 \mathrm{GHz}$ for $\mathrm{TE}_{01}$ and $\mathrm{TE}_{02}$ modes and a $4.76 \mathrm{~cm}$ diameter waveguide at $8.6 \mathrm{GHz}$ for a $\mathrm{TM}_{01}$ mode.

Comparison of the theoretical results and the experimental data is shown in Fig. 7 in the $\phi=0^{\circ}$ plane for the $\mathrm{TE}_{01}$ mode radiating from a step-cut baffle . Note that even for this simple theory, there is good agreement between the theoretical and experimental results for the main lobe and the first side lobes. In the $\phi=90^{\circ}$ plane, shown in Fig. 8, the quantitative agreement is not quite as good for the side lobes but is still very close for the main lokes and there is good qualitative agreement over the entire range. Figure 9 shows the theoretical and measured azimuthal radiation patterns for the same baffle and input mode. (The capability to make azimuthal radiation patterns is a new feature for our radiation pattern measurement facility added this past year.) The theoretical and measured radiation patterns of the $\mathrm{TE}_{01}$ mode at $60 \mathrm{GHz}$ radiating from a slant cut baffle is shown in Fig. 10. We are hopeful that the good agreement that we have found here is evidence that this method will also yield better results for WG modes than those previously used.

The simple equivalence principle model that we have developed gives the best agreement with measurements of any that we have seen to date. However, we feel that it can still be improved. For example, in this model, the currents on the baffle are taken to remain of constant amplitude over the entire surface right up to the baffle edge where they are taken to abruptly stop. Of course, this is not exactly correct. We have, in a heuristic manner, considered in our theory several simple current distributions which depart from the constant amplitude case. Remarkably, these variations did not significantly improve the agreement 


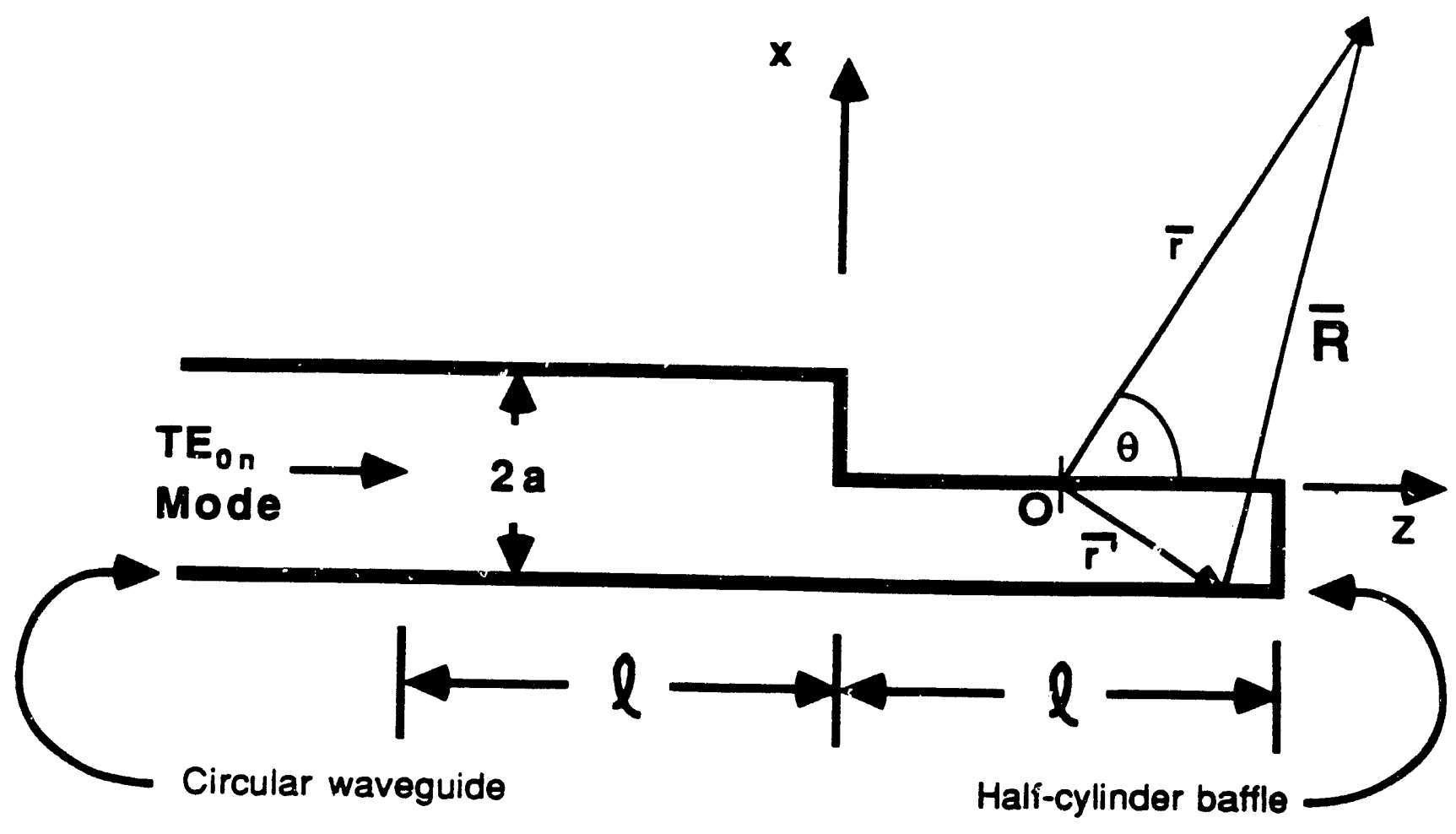

Fig. 6. Side view of the half-cylinder baffle for a $T E_{0 n}$ mode Vlasov launcher with the coordinate system used for the equivalence-principle model. 


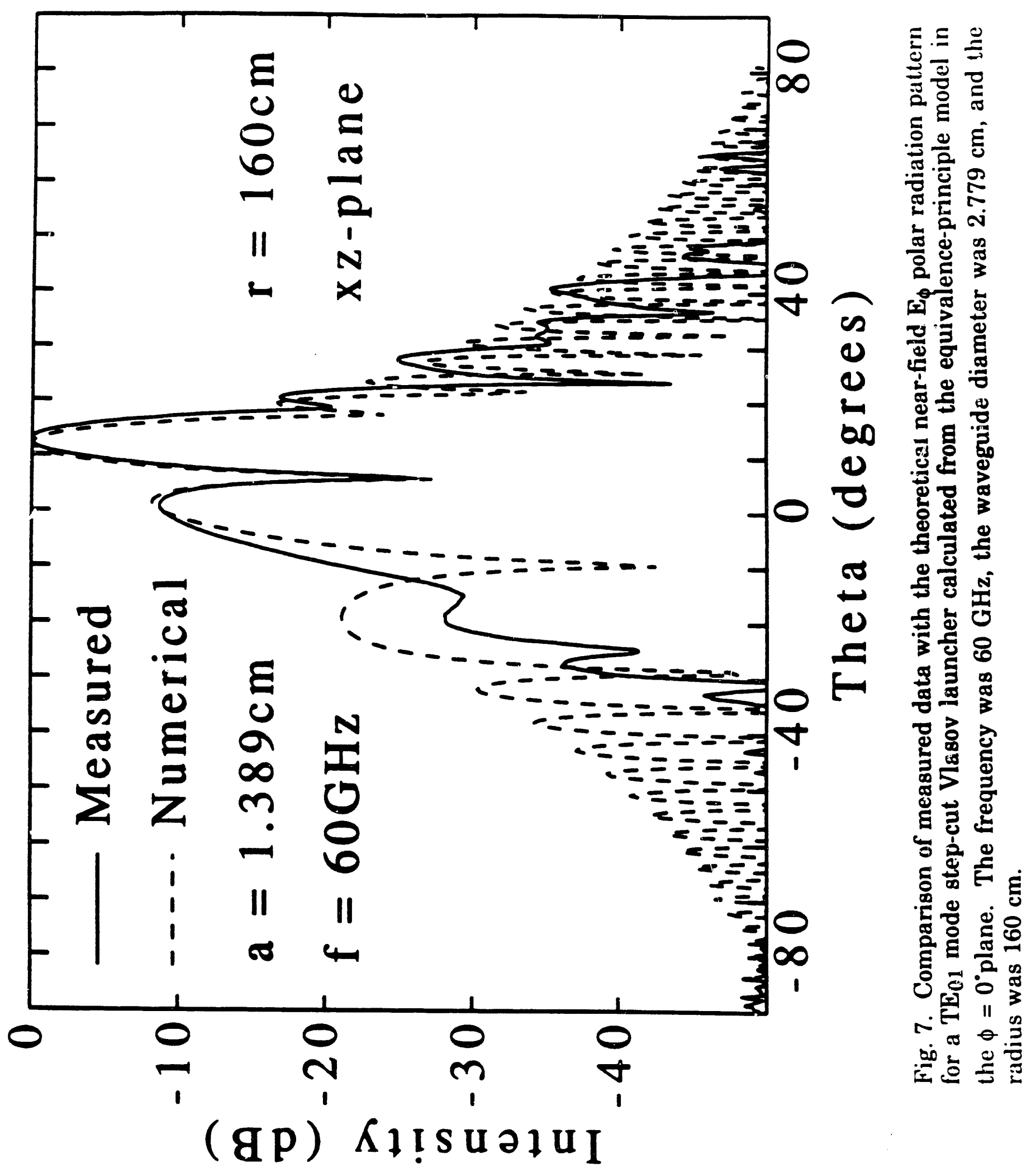




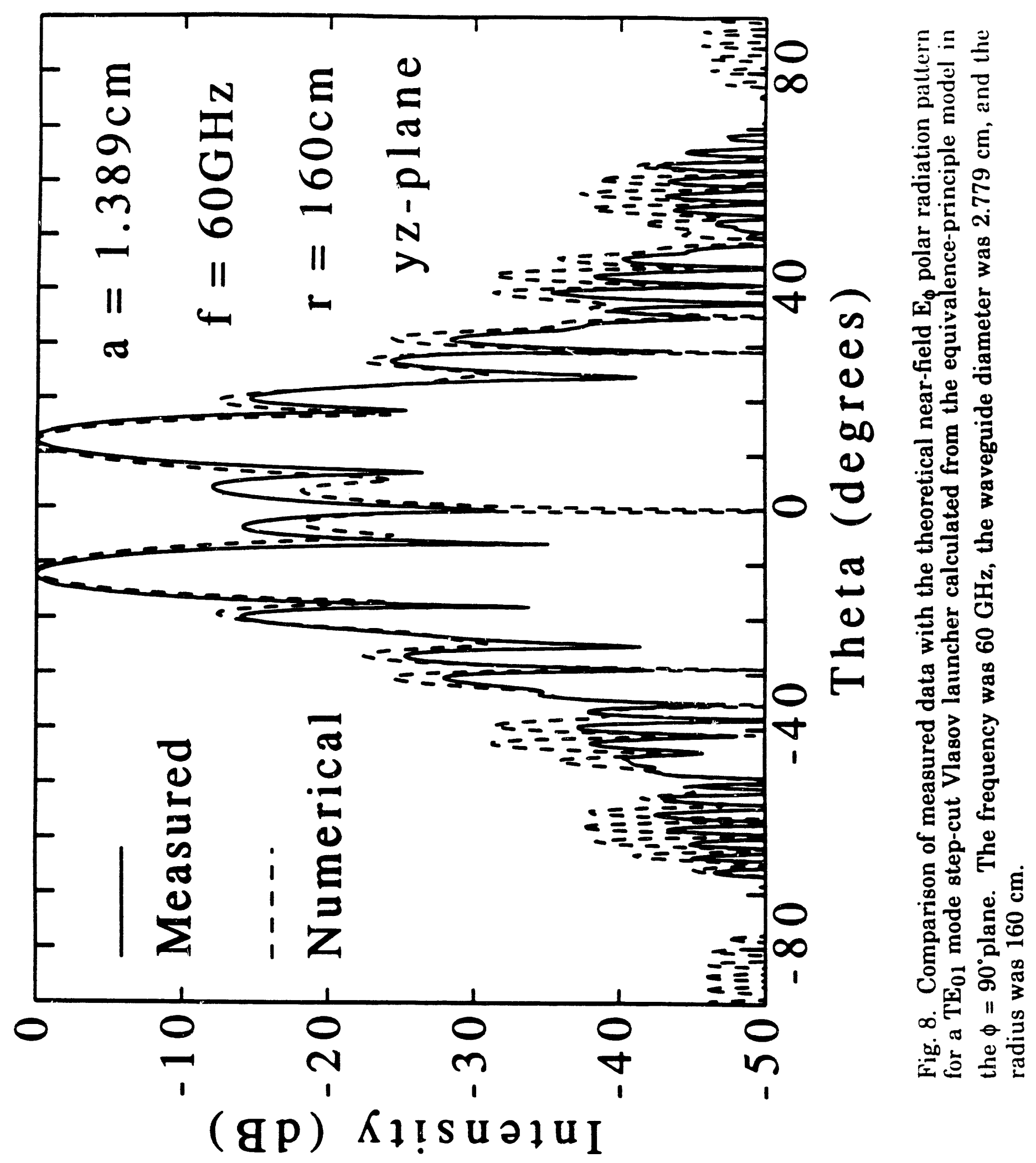



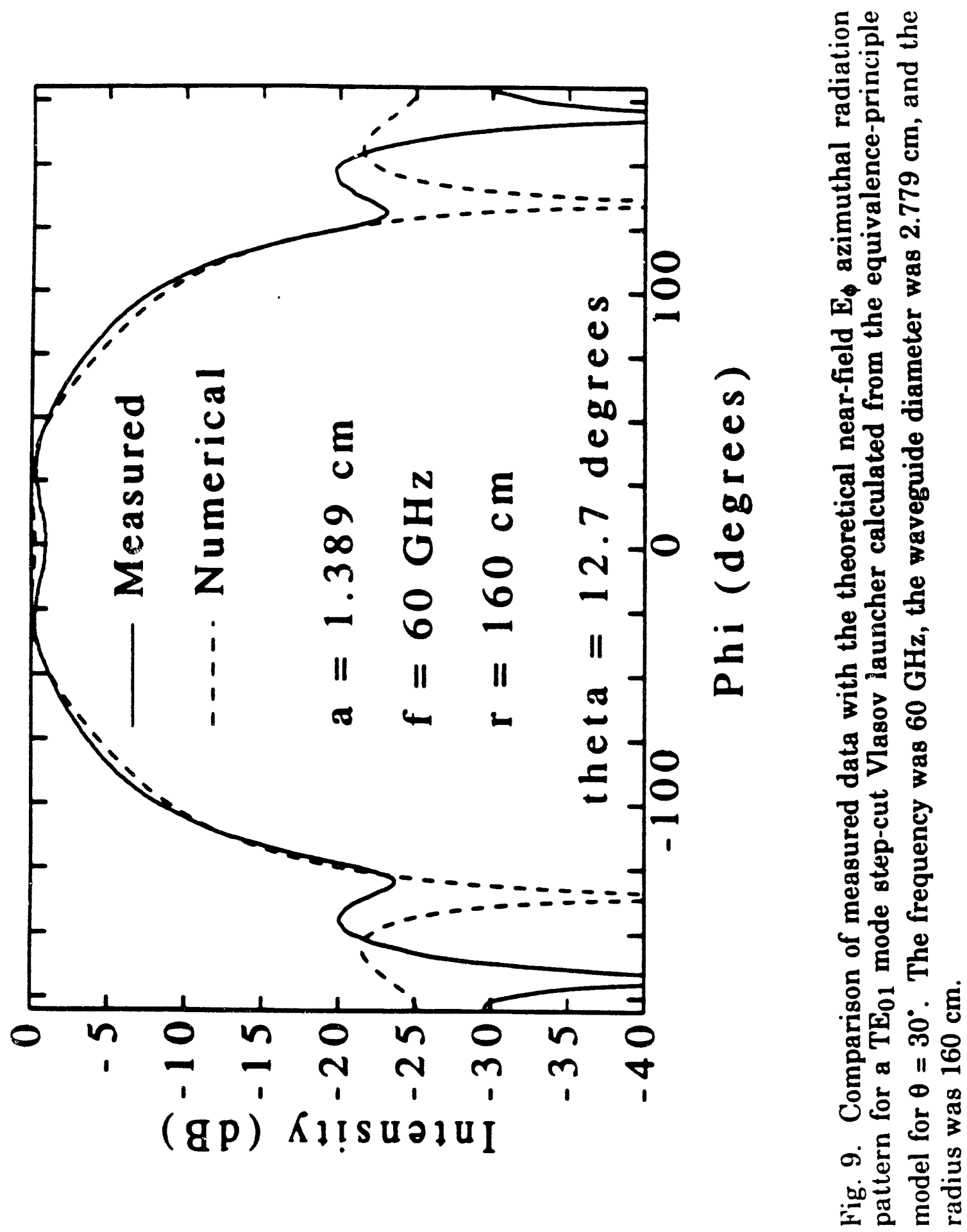


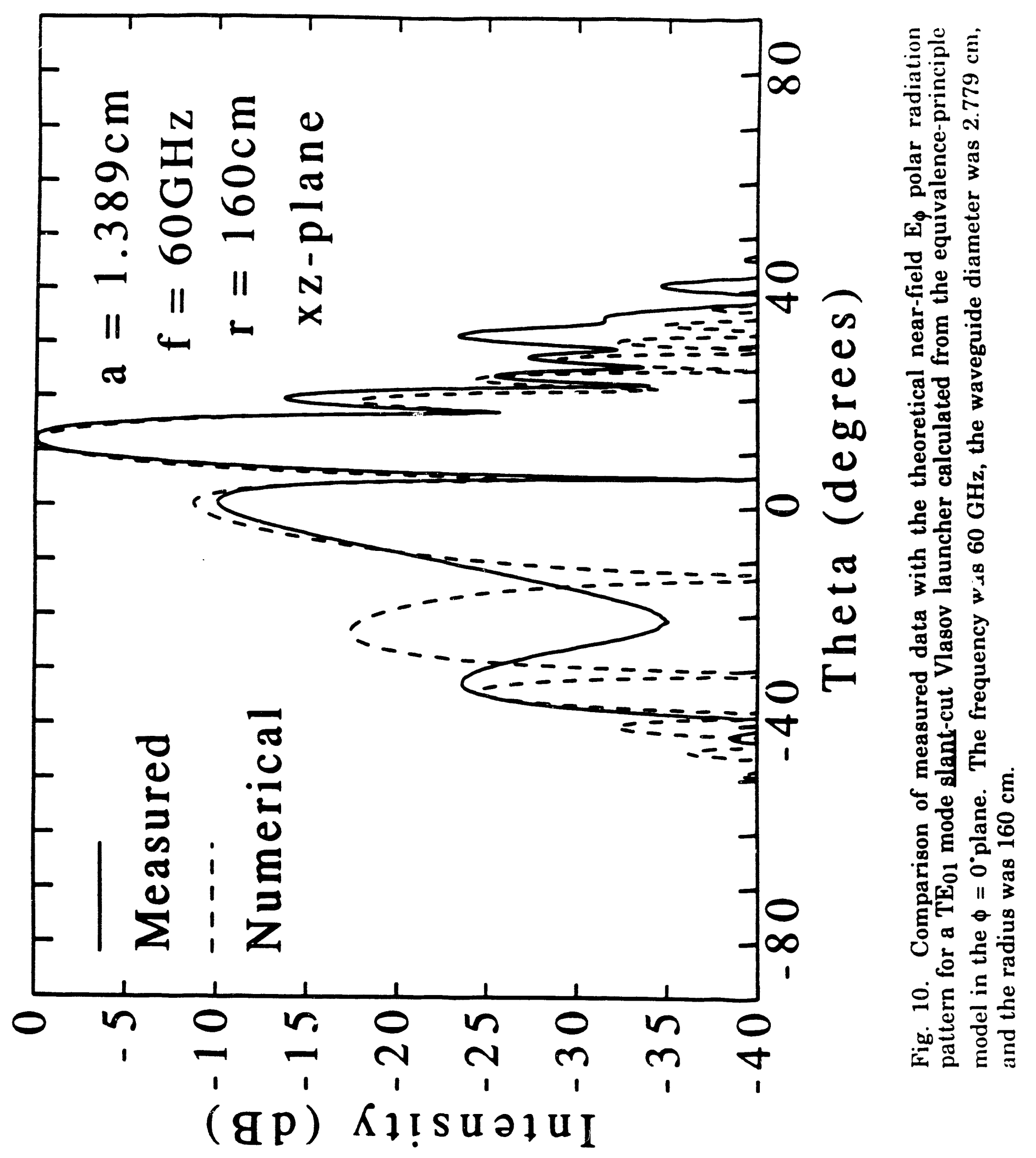


between theory and experiment. In the next year, we will make field measurements close to the baffle to try to determine a more accurate model for the current distribution on the baffle. This will also be done for WGM baffles.

Work is currently underway on the theoretical patterns for WG mode launchers and these will be compared with theory this summer when one or more of our WG mode generators is operational. Baffle current measurements will also be made on whispering gallery mode baffles as indicated above.

We have also used our ray-optic design programs to design a two dimensional reflector system which takes the experimental output from a $\mathrm{TE}_{01}$ Vlasov feed and produces an output beam which is Gaussian in the transverse direction. The reflector system is shown in Fig. 11 and the ray diagram is shown in Fig. 12. Since we are able to design efficient mode converters from WG modes to high order $\mathrm{TE}_{0 \mathrm{n}}$ modes (See Sec. II-B-1 which follows), at moderately large radius, the possibility exists of performing this conversion and then using a $\mathrm{TE}_{0 \mathrm{n}}$ mode type Vlasov antenna system. Thus the $\mathrm{TE}_{0 \mathrm{n}}$ mode Vlasov launchers could take on additional importance. This type of antenna system may not have any particular advantage over WG mode Vlasov launchers but the possibility should be explored.

During the next year, we will also consider using small distortions in the waveguide just preceding the launcher and in the baffle to obtain a narrower radiation pattern from the baffle. This study may help us in the similar investigation for WGM launchers mentioned above.

\section{II-B. Whispering-Gallery Mode Generator Development}

In order to test the Vlasov launcher and mode conveiter designs being developed for whispering-gallery mode gyrotrons, it is necessary to generate at low power the same high-azimuthal-index modes that the gyrotrons produce. We have considered two possible methods of generating such modes. The first would use a system of mode converters to change the $\mathrm{TE}_{01}$ mode to the desired WG mode, for example the $\mathrm{TE}_{15,2}$ mode. The second method would use an azimuthal array 




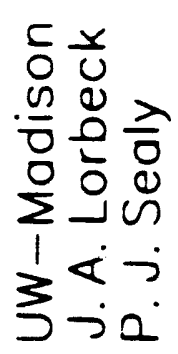

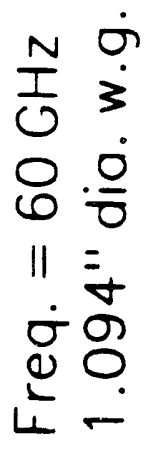

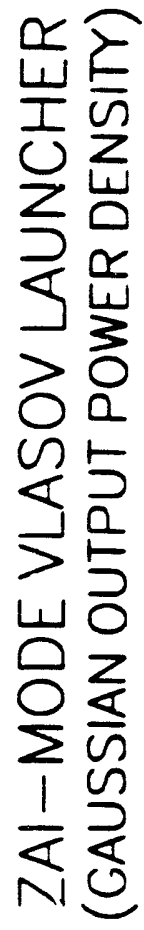

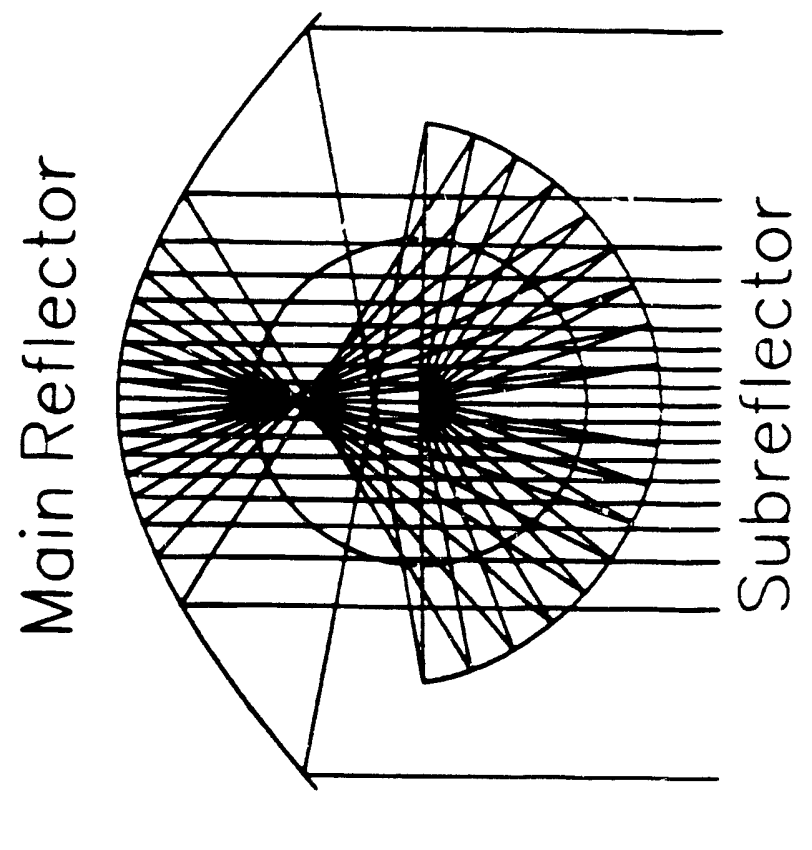

]

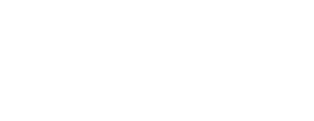


of apertures in a circular waveguide and fed by a rectangular waveguide wrapped around the circular guide to generate the whispering-gallery mode.

\section{II-B-1. Generation of Low-Power Whispering-Gallery Modes With Perturbed-Wall Waveguide Mode-Converters}

Our initial design effort, currently being fabricated, has focused on producing the $\mathrm{TE}_{15,2}$ mode at $110 \mathrm{GHz}$. This is the mode and frequency of the 500 $\mathrm{kW}$ gyrotron developed by Varian Associates for use at General Atomics. This will support our goal of the development of 2-D and 3-D Vlasov launcher systems for possible use with these gyrotrons for ECR heating as discussed in Sec. II-A-1. The first component in this system is a mode converter from standard F-band $\mathrm{TE}_{10}$ mode rectangular waveguide to the $\mathrm{TE}_{01}$ mode in a small diameter circular waveguide. This component is commercially available from Alpha TRG. The next component in the series is a varying radius $\mathrm{TE}_{01}-\mathrm{TE}_{07}$ mode converter which will also serve as an uptaper. The wall profile of this converter is shown in Fig. 13. Figure 14 shows the mode amplitude content as a function of longitudinal position along the converter. The third component in this system is a helical multifoil mode converter [3] to transform the $\mathrm{TE}_{07}$ mode into the rotating $\mathrm{TE}_{15,2}$ mode. An exaggerated diagram of this mode converter is shown in Fig. 15. The helical multifoil has a waveguide wall profile defined by

$$
a(z)=a_{0}+\Delta a(z) \cos \left(m \phi \pm k_{p} z\right)
$$

where $a_{0}$ is the average radius, $k_{p}$ is the longitudinal perturbation wave number, and in this case $m=15$. This design of this $\mathrm{TE}_{07}-\mathrm{TE}_{15,2}$ mode converter is approximately $17.7 \mathrm{~cm}$ long and, in this case, the maximum value of $\Delta \mathrm{a}$ is .0107 in.

Fig. 16. shows the amplitude of several of the most important modes in this converter as a function of distance along the transducer. The two curves labeled $\mathrm{TE}_{15,2}$ represent the cos $\mathrm{m} \phi$ and $\sin \mathrm{m} \phi$ solutions for the $\mathrm{TE}_{15,2}$ waveguide mode. It is necessary for both of these to have the same amplitude and a phase difference of $90^{\circ}$ at the end of the converter in order to have a pure rotating mode. In this calculation, thirty-two modes were considered; $8 \mathrm{TE}_{0 \mathrm{n}}$ modes, $8 \mathrm{TM}_{0 \mathrm{n}}$ modes, and 


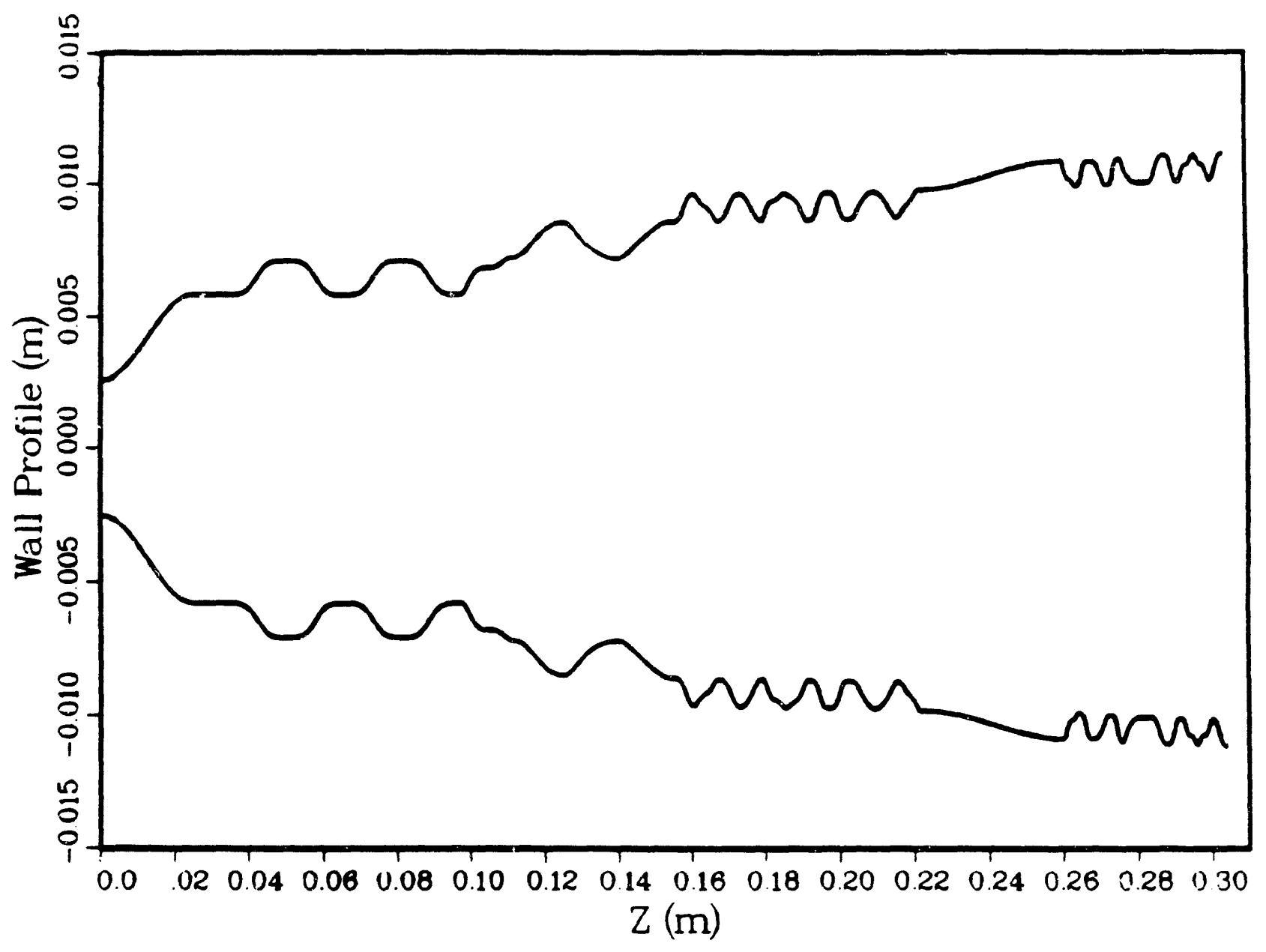

Fig. 13. Exaggerated wall profile of the $110 \mathrm{GHz}, \mathrm{TE}_{01}-\mathrm{TE}_{07}$, varying-radius mode converter. The radial scale is expanded compared to the longitudinal scale. 


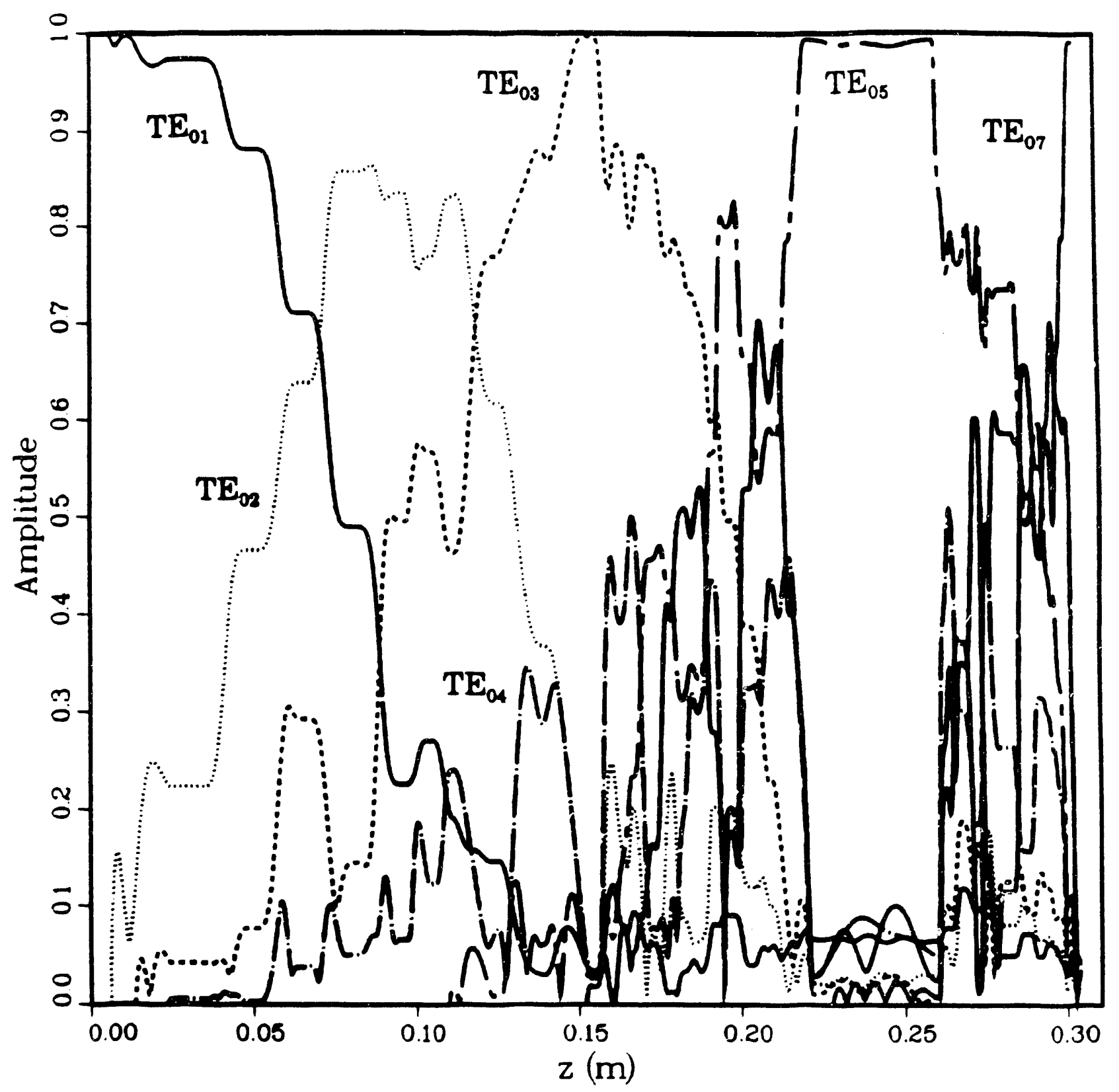

Fig. 14. Graph of mode amplitude versus longitudinal distance for a $110 \mathrm{GHz}$, $\mathrm{TE}_{01}-\mathrm{TE}_{07}$, varying-radius mode converter. The output mode purity is $99.2 \%$. The ohmic loss is $1.39 \%$. 


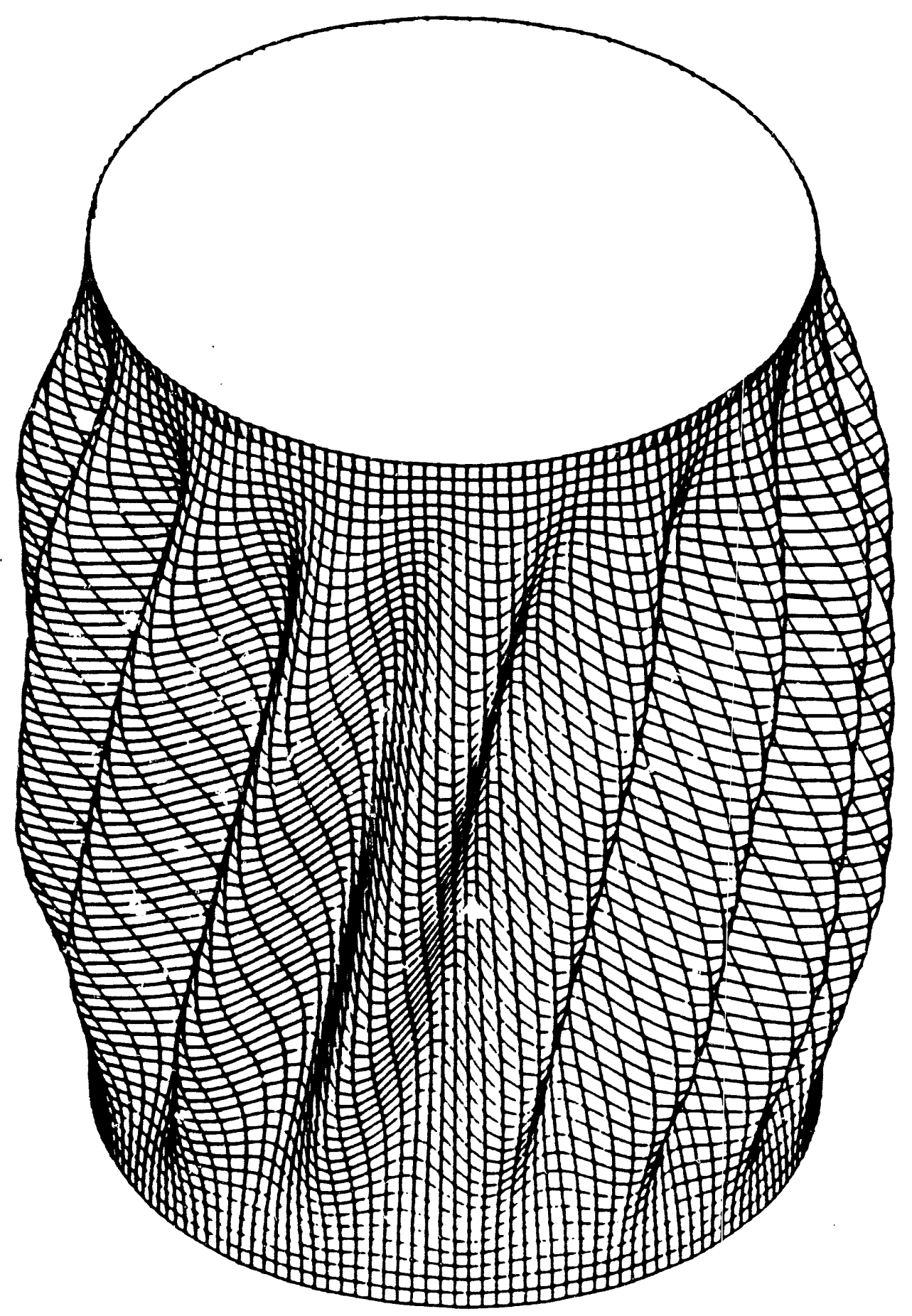

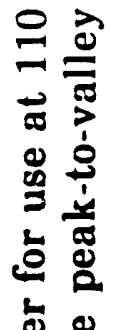

놀

ह.

ठ․․

응

응

녕 옹

떤 8

ธ워으

또 홍흥

둥

롱

․․ㄹ

용

용

$\infty$ 禹

능 은

E $\infty$

횽응

D

율년

옹 논

क

吾至

总

気

[घ] 를

10

站弪 


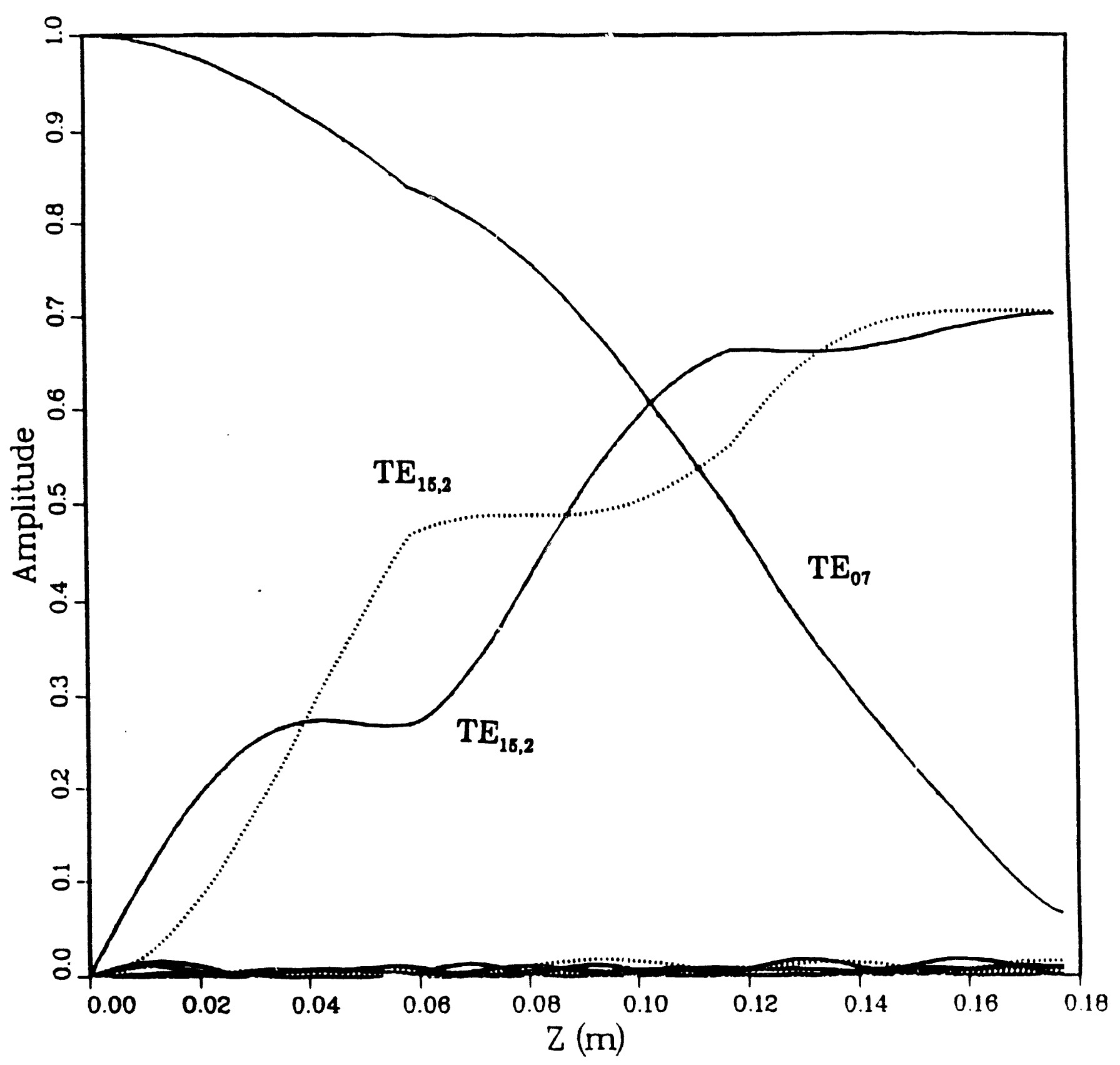

Fig. 16. Graph of mode amplitude versus longitudinal distance for a $110 \mathrm{GHz}$ $\mathrm{TE}_{07}-\mathrm{TE}_{15,2}$ helical multifoil mode converter. The output mode purity is $99.5 \%$ for a single mode input. The ohmic loss is $0.61 \%$. 
$16 \mathrm{TE}_{15,2}$ modes. The computed output mode purity is $99.5 \%$ with an ohmic loss of $0.61 \%$.

The fabrication of these devices is somewhat more difficult than for the usual mode converters which we have designed. As for our previous varying radius type mode converters, the helical multifoil mode converters will be electroformed onto aluminum mandrels and the mandrels eaten out with a sodium hydroxide solution. However, the waveguide wall is now much more complicated than for the simple varying radius converters which were cut on a numerically controlled lathe. The helical multifoil mandrels have to be cut on a four-axis numerically controlled mill. In order to have the mandrel fabricated, it was necessary to supply the machinist with the tool path profiles for the helical multifoil wall. Figure 17 shows the cutting position for a ball-end mill for the case of eight cuts per multifoil period. The design of Thumm and Jacobs [3] had a much smaller average radius and a maximum perturbation radius of only $.0015 "$. This requires extremely exacting tolerances on the machining. The tolerances are less stringent in our design. However, fabrication has still met with difficulty.

\section{II-B-2. Generation of Low-Power Whispering-Gallery Modes With Aximuthal Aperture Arrays}

A second method of generating high-azimuthal-index rotating modes was also considered over this last year. In this method, an azimuthal array of equally spaced apertures is used to excite the desired mode in a circular waveguide from a dominant mode rectangular waveguide wrapped around it. A drawing of a cross section of this azimuthal-aperture-array mode converter (AAAMC) is shown in Fig. 18. In the first design, a simple short circuit was placed in the circular waveguide on one side of the aperture array, as shown in Fig. 19, to allow unwanted $\mathrm{TE}_{6 \mathrm{n}}$ modes to be "tuned" out.

Since a large part of this study was to be experimental, it was necessary to work at $60 \mathrm{GHz}$ where we had a full complement of equipment. We will have full experimental capabilities at $110 \mathrm{GHz}$ by the end of this summer. 

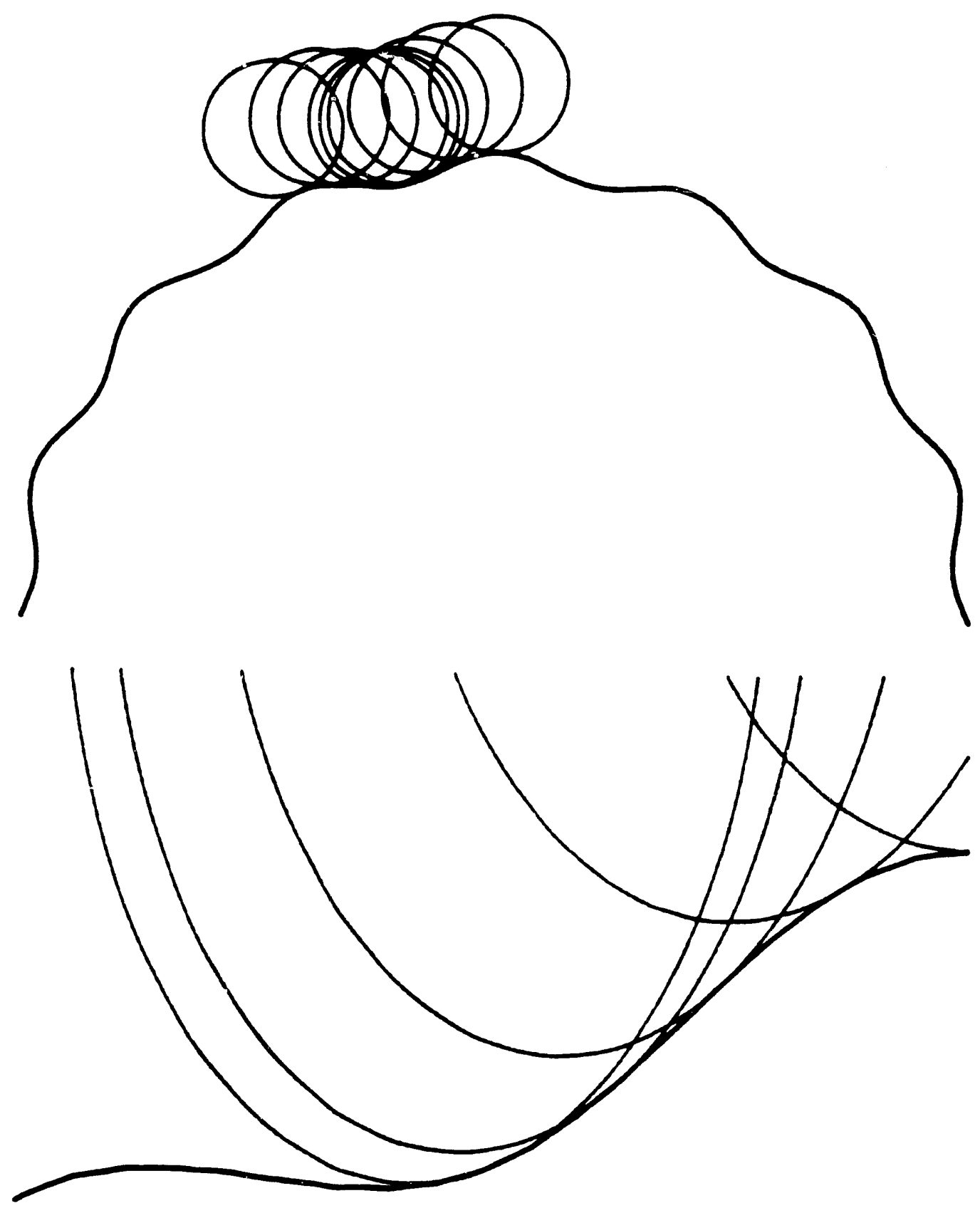

Fig. 17. a) Diagram showing a cross-section of the helical multifoil mode converter with "tool-cut" circles for the case of 8 cuts per period. b) Expanded view of one period of the top drawing with the vertical dimension expanded much more than the horizontal. 


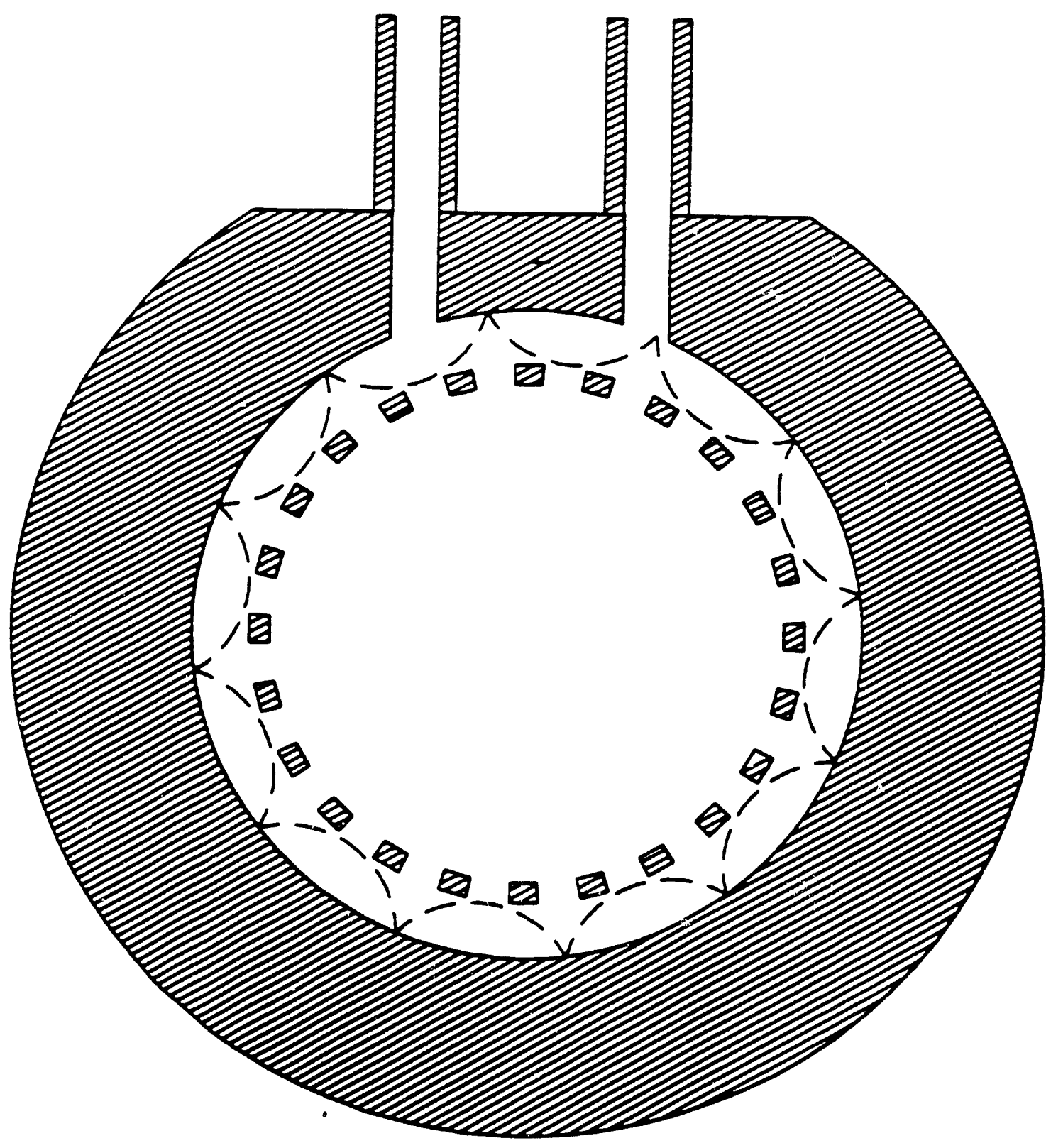

Fig. 18. Transverse cross-section of the azimuthal-aperture-array structure used to test the feasibility of generating rotating high-azimuthal-index modes in highly overmoded circular waveguides. 6,12 , and 24 apertures have been used up to this point. 


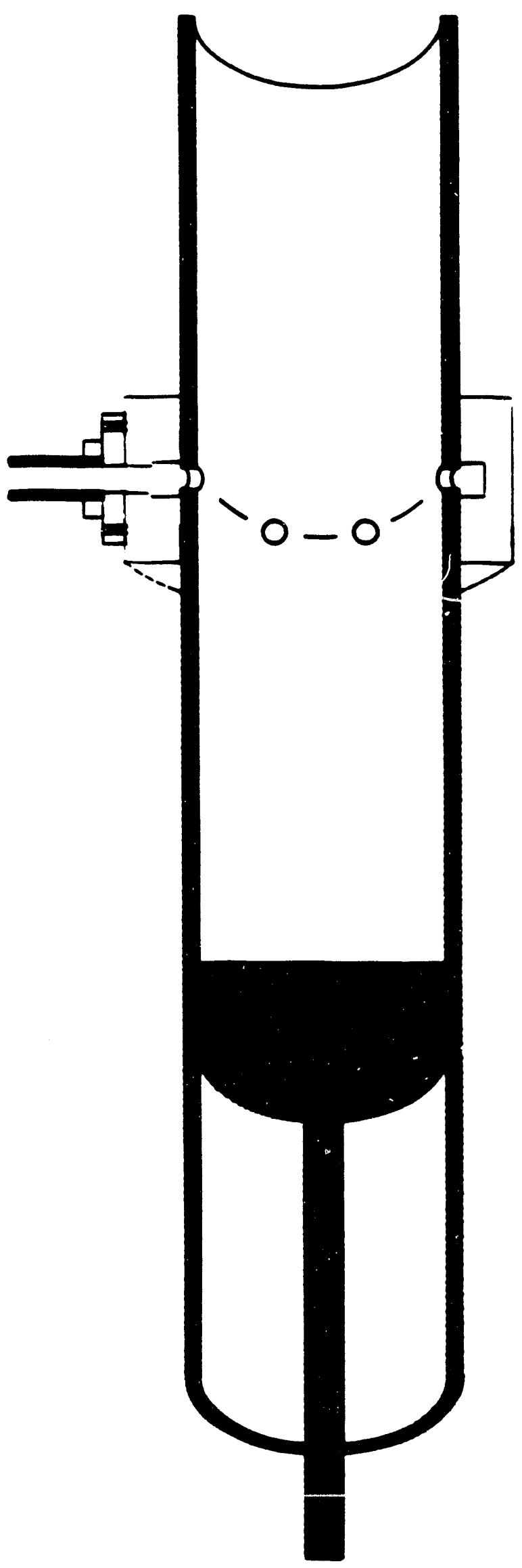

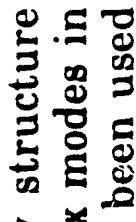

元

을

도

め ळ

3 콕

․ㅗㅇ

(

$\approx \frac{1}{50}$

르을

잉

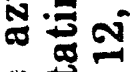

을 웅

4. ․ㅗㅇ

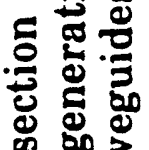

on 203

品 3

은 곻

홀

웡

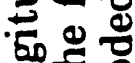

틍호응

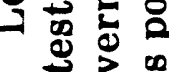

ค่ 0 己.

$-1 \geqslant 0$

i 
In our initial work on this device, a circular waveguide with an inner diameter of 1.094" was used because we had the correct size flanges and a kspectrometer for this diameter. In our proof of principal investigation of this typ of mode converter, we chose to try to produce the $\mathrm{TE}_{6 \mathrm{n}}$ modes because, at a frequency of $60 \mathrm{GHz}$ and this waveguide diameter, the bounce angle, will be similar to that produced by the $\mathrm{TE}_{15,2}$ mode at $110 \mathrm{GHz}$. However, this waveguide diameter allowed the first three $\mathrm{TE}_{6 \mathrm{n}}$ modes to propagate at $60 \mathrm{GHz}$ and it proved difficult to eliminate two of them without incorporating a cavity in the circular waveguide. Thus we changed to a .811 " inner diameter circular waveguide in which the $\mathrm{TE}_{63}$ mode is cutoff.

As shown in Fig. 18, the $\mathrm{TE}_{10}$ mode was fed into the circumferential waveguide through one of the rectangular waveguide ports and the second was terminated in a movable short circuit. The circumferential waveguide was designed to be exactly six wavelengths long at $60 \mathrm{GHz}$. We have determined that, with the proper spacing between the two rectangular waveguide ports and the correct position of the short in the second rectangular port, a travelling wave resonator can be formed in the azimuthal rectangular waveguide. An array of 24 azimuthal apertures was drilled in the circular waveguide to provide the mode selective coupling. When a travelling wave exists in the rectangular waveguide, a rotating mode is set up in the circular waveguide. The rectangular waveguide short can also be positioned so that the wave in the azimuthal rectangular waveguide is a standing wave. This produces a stationary mode in the circular waveguide. The movable short circuit placed in the circular waveguide behind the aperture array allows for selectively "tuning out" either the $\mathrm{TE}_{61}$ or $\mathrm{TE}_{62}$ mode and, with proper choice of position, to reduce the level of some other spurious mode(s) as well.

Figures 20 and 21 show a comparison of the theoretical and measured openend $E_{\theta}$ and $E_{\phi}$ polar radiation patterns for the $\mathrm{TE}_{62}$ mode as produced by this device. Figure 22 shows the agreement between the theoretical and measured azimuthal radiation patterns for $E_{\theta}$ when the rectangular waveguide short circuit was adjusted for a stationary mode When the rectangular waveguide short circuit was adjusted for a rotating mode, the azimuthal pattern indicated approximately 36 time more power in the mode rotating in one direction than the 


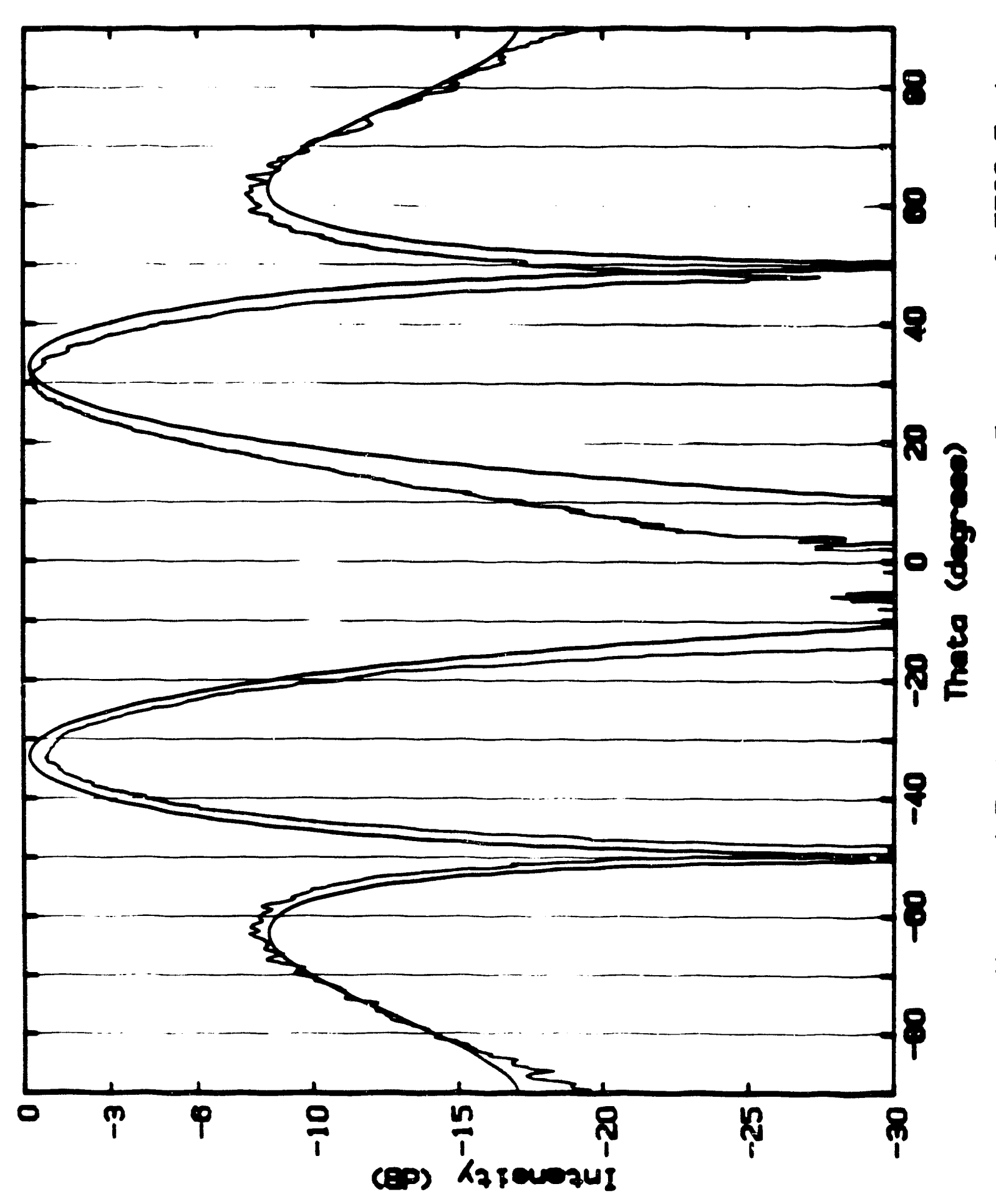

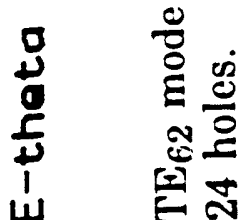

约

-

무

1 芩

- 10

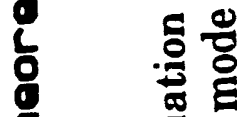

ㄴ.

한

5

용

능

잉

ธิ

ํㅗㅇ

主

g) 돌

" छ

닐

لإ

0
$\frac{1}{5}$
$\frac{0}{2}$
$\frac{0}{2}$

롤

능

ธ ํํㅇ

葛导

ํํํ르

일 


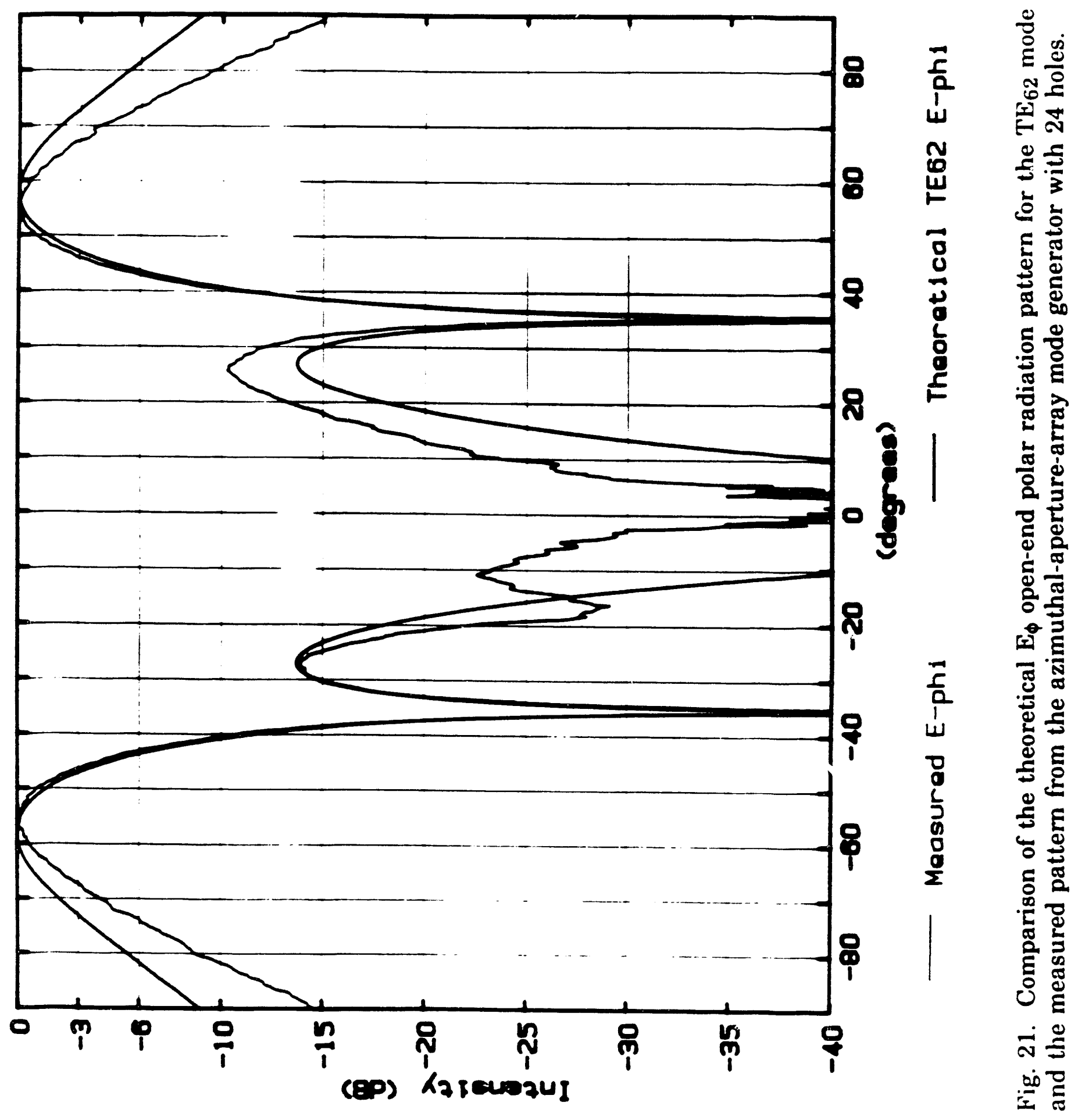




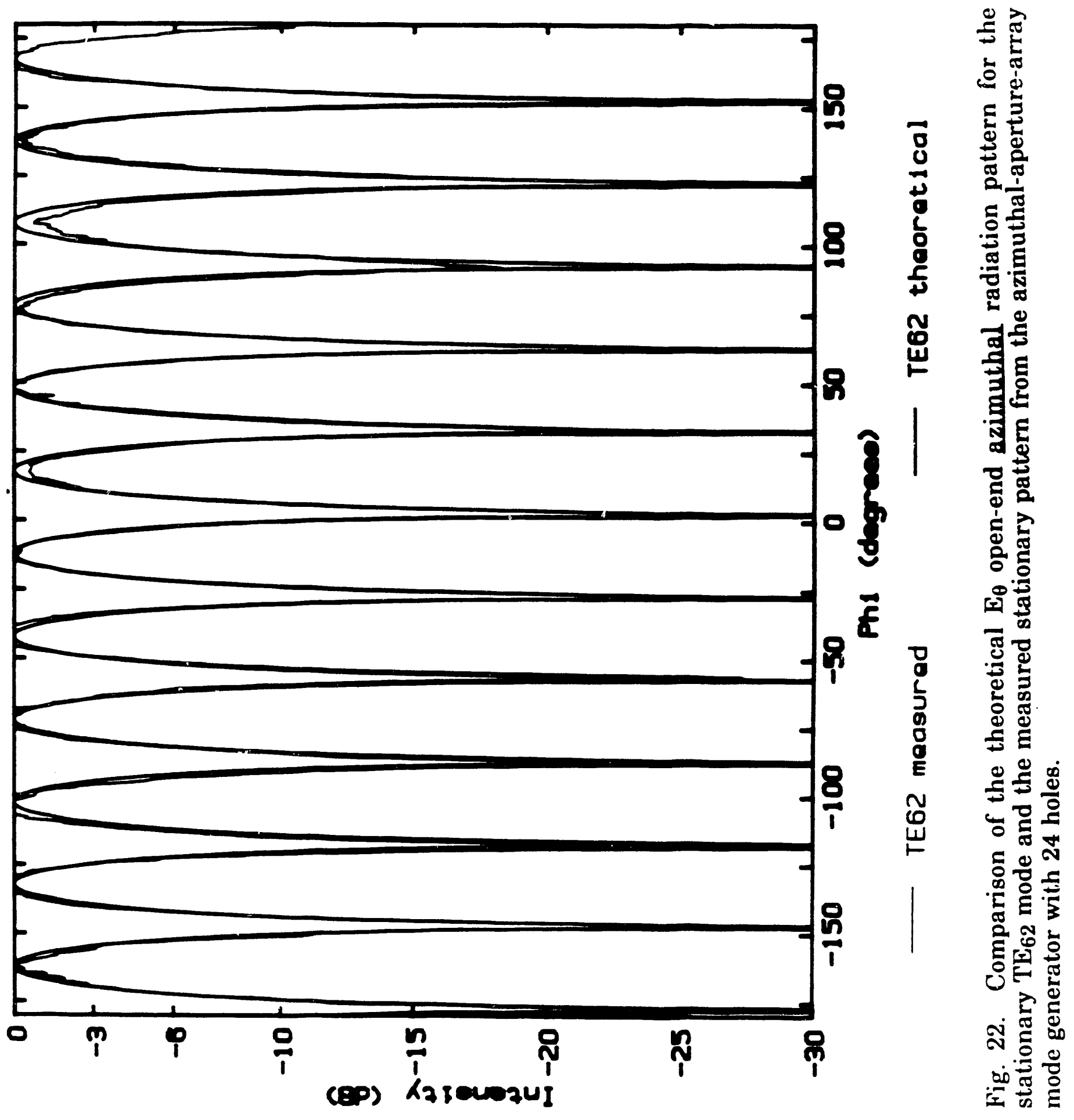


other. This ratio can be improved by changing the electrical length between the two rectangular ports slightly.

Our future work on this device will include the investigation of a triple concentric short circuit in the circular waveguide and fabricating and testing a design for producing the $\mathrm{TE}_{15,2}$ and $\mathrm{TE}_{22,2}$ modes at $110 \mathrm{GHz}$. We will also explore the use of creating a cavity in the circular waveguide probably with a wire screen. With such a cavity we hope to be able to obtain modes with higher radial indexes than 2. This will be important for future gyrotrons which operate at higher frequencies.

After we had begun the consideration of this device, some work by Furuno [4] was brought to our attention where this method had been used, apparently successfully, for generating a nonrotating $\mathrm{TE}_{81}$ mode at $16.15 \mathrm{GHz}$ in a less overmoded waveguide than the cases that we will be interested in. In this work apparently only 8 apertures were used to generate a relatively pure $\mathrm{TE}_{\mathbf{8 1}}$ mode. We had thought that at least 16 apertures would be necessary to generate the $\mathrm{TE}_{81}$ mode without exciting the $\mathrm{TE}_{01}$ mode. We now believe that Furuno's results were in error or that we somehow misinterpreted them. Our measurements indicate that the device that we believe that Furuno described would have generated a substantial amount of unwanted $\mathrm{TE}_{01}$ mode.

\section{II-C. Mode Converter Development}

We have had a strong program in mode converter development over the last several years. This last year, our major effort in mode converter development was in the WGM generators described in Sec. B above. Previously we have also developed a design for a mode converter and uptaper combination of the type needed for use in the $110 \mathrm{GHz} \mathrm{TE}_{22,2}$ radial extraction gyrotron. J. Neilson of Varian has determined that, with the appropriate phase difference, a specific mode combination will have high transmission with low mode conversion across the azimuthal gap through which the electron beam will be diverted [5]. Our effort was done in parallel with J. Neilson at Varian. When it was found that he achieved similar results for the same type of converter, work on this device was 
discontinued. An offer was extended to check his design profile with our computer program for verification which was done this year.

\section{II-D. Taper Designs}

Last year, we began working on a computer technique to obtain optimized tapers based on optimal control theory. A preliminary version of such a program is currently running and is being tested for a $\mathrm{TE}_{02}$ mode where we have a good analytic optimization method. However, the computer technique does not give results for the $\mathrm{TE}_{02}$ mode as good as those that we obtain an optimizing analytic method at this time. We will continue to explore both analytic and numerical optimizing techniques in the future.

\section{II-E. Other Activities}

\section{II-E-1. Attenuation and Phase Constants Near Cutoff and Mode Coupling Due to Wall Losses}

The whispering-gallery-mode gyrotrons currently being developed have cavities which operate very close to the cavity waveguide cutoff. Also, in the uptapers from these cavities, modes which can be strongly coupled by the radius change pass through cutoff. Thus in the gyrotron cavity and in the smaller sections of the uptaper, it is important to use accurate expressions for the attenuation and phase constants near and below cutoff. The usual simple expressions for the attenuation and phase constants are not valid in the range very close to cutoff or below cutoff. The group at Varian has been using a perturbational approximation for the phase and attenuation constant derived by Jackson [6]. Last year, we checked this result by a more complete eigenmode expansion method and found it to be quite accurate.

Loss is a more important factor for whispering-gallery type modes than for $\mathrm{TE}_{0 \mathrm{n}}$ modes. Thus it is valuable to check that the usual assumption that the mode coupling due to wall losses is small compared to wall-perturbation coupling is still valid. This last year the eigenmode expansion method has been used to find 
the coupling coefficients between modes coupled by loss in the waveguide walls: For waveguides of good conductor such as copper, these coupling coefficients have indeed been found to be about two orders of magnitude smaller than those due to typical wall perturbations. Their effect is normally further diminished by the fact that the coupling is normally continuous Thus, under usual conditions, the small amount of power that is transferred by this mechanism to some spurious mode in the first section of a converier transfers back in large measure to the original mode in the next.

\section{II-E-2. Phase Pattern Measurement}

We have continued work over the last year on adding the capability of measuring and processing the relative phase pattern of the radiation from an open-end waveguide or a Vlasov launcher. Phase pattern information will be useful in mode content determination by the open-end radiation pattern method. It will also be valuable in the later stages of our Vlasov launcher work where phase front information is important for proper reflector design. However, accurate phase pattern data becomes more difficult to obtain as frequency is is increased. We have developed the capacity to take accurate phase pattern data for another program at $8.6 \mathrm{GHz}$ where wavelengths are longer than at 60 and 110 $\mathrm{GHz}$ making the problem easier. We have also developed a flexible line for $60 \mathrm{GHz}$ which can be used to bring the phase reference signal to the detector as the receiving horn turns.

\section{II-E-3. Radiation Pattern Measurement Facility Improvement}

We added an azimuthal rotator to our radiation pattern measurement facility this spring. The rotator was modified so that it is compatible with our previous data acquisition system. This now gives of the capability of making azimuthal radiation pattern measurements as well as polar pattern measurements.

Several minor improvements were also made to our radiation pattern data acquisition system over the past year. 


\section{II-F. Special Activities}

During the last 12 months, Professor Vernon participated in three gyrotron program reviews, two at Varian and one at the University of Wisconsin. He also participated in scientific exchanges to Japan and the Soviet Union, making presentations on both trips. A presentation was also given at the High-Power MM-Wave Workshop in Cocoa Beach in December 1990. Three presentations were given at the December 1990 Infrared and Millimeter Wave Conference and two at the IEEE Antennas and Propagation Society Symposium in June 1991. 


\section{REFERENCES}

[1] N. Vlasov, L.I. Zagryadskaya, and M.I Petelin,"Transformation of Whispering Gallery Mode, Propagating in a Circular Waveguide, into a Beam of Waves," Radio Eng. Electron. Phys., Vol 21, No. 10, p. 14, $19 \%$

[2] M. Iima et al., "Measurement of Radiation Field from an Improved Efficiency Quasi-Optical Converter for Whispering-Gallery mode," Fourteenth Int. Conf. on Infrared and Millimeter Waves, Wurzburg, West Germany, pp. 405-406, Oct. 1989.

[3] M. Thumm and A. Jacobs, "In-Waveguide $\mathrm{TE}_{01}$-to-Whispering Gallery Mode Conversion Using Periodic Wall Perturbations," Thirteenth Int. Conf. on Infrared and Millimeter Waves, Honolulu, Hawaii, pp.465-466, Dec. 1988.

[4] D. S. Furuno, "Theory, Design, and Operation of High Harmonic GyroAmplifiers," PhD. Dissertation, Univ. Calif. - Los Angeles, 1987.

[5] J. Neilson, Private Communication.

[6] J. D. Jackson, Classical Electrodynamics, 2nd ed., Wiley, 1975, pp. 350-353. 


\title{
PUBLICATIONS RESULTING FROM PROJECT RESEARCH
}

\section{PUbLICATIONS AND PRESENTATIONS AT CONFERENCES PUBLISHING A SUBSTANTIAL DIGEST}

\author{
(As of August 15, 1991)
}

"Single-Period $\mathrm{TE}_{02}-\mathrm{TE}_{01}$ Mode Converter in a Highly Over-Moded Circular Waveguide," M. J. Buckley and R. J. Vernon, IEEE Trans. on Microwave Theory and Techniques, Vol. 39, No. 8, Aug. 1991, pp 1301-1306.

"Dual Shaped Dual-Reflector Antenna for a Whispering-Gallery-Mode Gyrotron," J. A. Lorbeck and R. J. Vernon, IEEE Antennas and Propagation Society International Symposium, London, Ontario, Canada, June 1991, Digest pp. 452-455.

"Equivalence-Principle Mode for Radiation from $\mathrm{TE}_{0 \mathrm{n}}$ and $\mathrm{TM}_{0 \mathrm{n}}$ Mode Step-Cut and Slant-Cut Vlasov Feeds," P. J. Sealy and R. J. Vernon, IEEE Antennas and Propagation Society International Symposium, London, Ontario, Canada, June 1991, pp. 1836-1839.

"Quasi-Optical Conversion of the Output from a Whispering-Gallery-Mode Gyrotron to a Free-Space Beam with Arbitrary Power and Phase Distribution Across both Transverse Dimensions of the Beam," J. A. Lorbeck and R. J. Vernon, 15th International Conference on Infrared and Millimeter Waves, Lake Buena Vista, FL, December 10-14, 1990, Digest pp 301-303.

"Equivalence Principle and Physical Optics Modeling of Radiation from $\mathrm{TE}_{0 \mathrm{n}}$ and $\mathrm{TM}_{\mathrm{On}_{\mathrm{n}}}$ Mode Vlasov Launchers," P. J. Sealy and R. J. Vernon, 15th International Conference on Infrared and Millimeter Waves, Lake Buena Vista, FL, December 10-14, 1990, Digest pp 216-218.

"Design of a Single-Period 8.6 GHz $\mathrm{TM}_{01}-\mathrm{TE}_{11}$ Serpentine Mode Converter and $\mathrm{TM}_{01}$ and $\mathrm{TE}_{11}$ Bends in Mrierately Overmoded Circular Waveguide," G. H. Luo, and R. J. Vernon, 15th International Conference on Infrared and Millimeter Waves, Lake Buena Vista, FL, December 10-14, 1990, Digest pp 434-436.

M. J. Buckley and R. J. Vernon, "Compact Quasi-Periodic and Aperiodic TE On $_{\text {Mode }}$ Converters in Overmoded Circular Waveguides for Use with Gyrotrons," IEEE Trans. on Microwave Theory and Techniques, Vol. MTT-38, pp. 712-721, June 1990

S. R. Seshadri, "Ideal Normal Mode Theory of a Serpentine Cylindrical Waveguide," IEE Proc., Vol. 136, Pt. H, No. 6, Dec. 1989.

P. J. Sealy and R. J. Vernon, "Vlasov Launchers for $\mathrm{TE}_{\mathrm{C}_{\mathrm{n}}}$ and High-Azimuthal-Index Rotating Modes," 14th International Conference on In/rared and Millimeter Waves 
(IEEE), Wurzburg, West Germany, October 2-6, 1989, Digest pp 158-159.

G. H. Luo and R. J. Vernon, "Varying-Radius Waveguide Mode Converters for Gyrotrons Producing High-Azimuthal-Index Rotating Modes," 14th International Conference on Infrared and Millimeter Waves (IEEE), Wurzburg, West Germany, October 2-6, 1989, Digest pp 160-161.

P. J. Sealy and R. J. Vernon, "Low-Power Investigation of $T E_{0_{n}}, T M_{0_{n}}$, and Rotating $T E_{m 1}$ and $\mathrm{TE}_{\mathrm{m} 2}$ Mode Vlasov Launchers," Progress in Electromagnetics Research Symposium, July 25-26, 1989, Boston, Mass. (Invited Talk)

G. H. Luo and R. J. Vernon, Varying-Radius Mode Converters For $140 \mathrm{GHz}$ Gyrotrons," Progress in Electromagnetics Research Symposium, July 25-26, 1989, Boston, Mass. (Invited Talk)

R. A. Schill, Jr. and S. R. Seshadri, "A Cylindrical Waveguide with Periodic Step Changes in the Radius: Interaction Between Transverse Magnetic and Transverse Electric Modes," J. Appl. Phys., Vol. 65, No. 11, pp. 4420-4427, June 1, 1989.

P. J. Sealy and R. J. Vernon, "Low-Power Investigation of $\mathrm{TE}_{0}$, and $\mathrm{TM}_{0 \mathrm{n}}$ Mode Vlasov Launchers," IEEE AP-S International Symposium, San Jose, CA, June 26-30, 1989.

J. A. Lorbeck and R. J. Vernon, "Determination of Mode Content and Relative Phase in Highly Overmoded Circular Waveguides by Open-End Radiation Pattern Measurement," IEEE AP-S International Symposium, San Jose, CA, June 26-30, 1989.

S. R. Seshadri, "Cylindrical Waveguide Mode Converter for Azimuthally Symmetric Transverse Electric Modes," IEE Proc., Vol 135, Pt. H, No. 6, pp. 420-425, Dec. 1988.

R. A. Schill, Jr. and S. R. Seshadri, "A Cylindrical Waveguide with Periodic Step Changes in the Radius: Interaction Between Two Transverse Magnetic Modes," J. Appl. Phys., Vol. 64, No. 11, pp. 6530-6535, Dec. 1988.

P. J. Sealy and R. J. Vernon, "Preliminary Low-Power Investigation of TE 0 Vlasov Launchers," Thirteenth Int. Conf. on Infrared and Millimeter Waves, Honolulu, Hawaii, p 125, Dec. 1988.

M. J. Buckley, G. H. Luo, and R. J. Vernon, "Very Short Quasi-Periodic and Aperiodic Mode Converters for 60 and $140 \mathrm{GHz}$ Gyrotrons," Thirteenth Int. Conf. on Infrared and Millimeter Waves, Honolulu, Hawaii, p 117, Dec. 1988.

M. J. Buckley, G. H. Luo, and R. J. Vernon, "New Compact Broadband High-Efficiency Mode Converters for High Power Microwave Tubes with $\mathrm{TE}_{0 \mathrm{n}}$ or $\mathrm{TM}_{0 \mathrm{n}}$ Mode Outputs," 
İEEE MTT-S International Microwave Symposium, New York, NY, May 23-27, 1988.

J. Shafii and R. J. Vernon, "Design of Shorter $\mathrm{TE}_{11}-\mathrm{HE}_{11}$ Mode Converters in Highly Overmoded Corrugated Circular Waveguide Using a Modified Chebyshev Method," IEEE AP-S International Symposium, Syracuse, NY, June 6-10, 1988.

M. J. Buckley, G. H. Luo, and R. J. Vernon, "New Compact Quasi-Periodic and Aperiodic Mode Converters for 60 and $140 \mathrm{GHz}$ Gyrotrons," Twelfth International Conference on Infrared and Millimeter Waves, Lake Buena Vista, FL, December 14-18, 1987.

R. A. Shill, Jr. and S. R. Sesh dri, "Mode Conversion in a Cylindrical Waveguide with Periodic Step Changes in the Radius," J. Appl. Phys., Vol. 62, No. 6, pp. 2178-2186, Sept.15, 1987.

R. J. Vernon, W. R. Pickles, M. J. Buckley, F. Firouzbakht, and J. A. Lorbeck, "Mode Content Determination in Overmoded Circular Waveguides by Open-End Radiation Pattern Measurement," IEEE AP-S / URSI International Symposium, Blacksburg, VA, June 15-19, 1987.

R. A. Schill and S. R. Seshadri, "Optimization of a Bumpy Cylindrical Waveguide Mode Converter" Int. J. of Infrared and Millimeter Waves, Vol. 7, No. 8, 1986.

R. J. Vernon and U. Rhee, "An Improved Design for $T_{E 2}-T E_{01}$ and $T E_{01}-T E_{11}$ Mode Converters for use with MM-Wave Gyrotrons," Tenth International Conference on Infrared and Millimeter Waves, Lake Buena Vista, FL, December 9-13, 1985.

R. J. Vernon, U. Rhee, and K. Audenaerde, "Methods of Designing Higher Efficiency, Shorter Length Periodic-Perturbation Mode Converters for Over-Moded Waveguides," Gyrotron User/Developer Meeting, San Diego, CA, November 12, 1985.

K. J. Vernon, B. R. Johnson, and D. J. Hoppe; "Design of a $\mathrm{TE}_{11}-\mathrm{HE}_{11}$ Mode Converter in a Highly Over-Moded Corrugated Circular Waveguide to be Used as a Reflector Feed for Plasma Heating," IEEE/AP-S Symposium, Vancouver, Canada, June 1985.

R. J. Vernon, D. J. Hoppe, R. E. Morrow, and J. C. Araneta, "Discussion of Selected Topics on a Beam Waveguide Launcher for Electron Cyclotron Resonance Plasma Heating," DOE Gyrotron User/Developer Meeting in Gaithersburg, MD, October 2 and $3,1984$.

R. J. Vernon, K. R. Audenaerde, J. B. Beyer, D. J. Hoppe, and J. E. Scharer, "A Beam Waveguide Launcher for Electron Cyclotron Resonance Plasma Heating," Department of Energy ECRH Transmission System Workshop Germantown, MD, June 16, 1983. 
R. J. Vernon, M. J. Buckley, and G. $H$. Luo, "Compact Broadband $\mathrm{TE}_{0 \mathrm{n}}-\mathrm{TE}_{01}, \mathrm{TE}_{01}-\mathrm{TE}_{11}$, and $\mathrm{TE}_{15,2}-\mathrm{TE}_{15,1}$ Mode Converters for use with MM-Wave Gyrotrons," Thirtieth Annual Meeting of the American Physical Society, Division of Plasma Physics, Hollywood Florida, Oct. 31- Nov. 4, 1988.

S. R. Seshadri, "Ideal Normal Mode Theory of a Serpentine Cylindrical Waveguide," URSI Radio Science Meeting, Syracuse, NY, June 6-10, 1988.

R. A. Schill Jr. and S. R. Seshadri, "Mode Conversion in a Cylindrical Waveguide with Periodic Step Changes in the Radius," URSI Radio Science Meeting, Syracuse, NY, June 6-10, 1988.

S. R. Seshadri, "High Frequency Transmission Systems for Gyrotrons," URSI Radio Science Meeting, Syracuse, NY, June 6-10, 1988.

R. J. Vernon, M. J. Buckley, and G. H. Luo, "New Compact $\mathrm{TE}_{03}-\mathrm{TE}_{02}, \mathrm{TE}_{02}-\mathrm{TE}_{01}$, and $\mathrm{TE}_{01}-\mathrm{TE}_{11}$ Mode Converters for Use with MM-Wave Gyrotrons," Twenty-Ninth Annual Meeting of the American Physical Society, Division of Plasma Physics, San Diego, CA, November 2-6 1987.

R. J. Vernon, W. R. Pickles, M. J. Buckley, F. Firouzbakht, and B. R. Johrson, "Mode Content Determination for Gyrotron Mode Converters by Open-End Radiation Pattern Measurement," Twenty-Eighth Annual Meeting of the American Physical Society, Division of Plasma Physics, Baltimore, MD, November 3-7, 1986.

D. J. Becker and R. J. Vernon, "Maximum Electric Fields in Circular Wave-guides Carrying Two Modes," Twenty-Seventh Annual Meeting of the American Physical Society, Division of Plasma Physics, San Diego, CA, November 4-8, 1985.

R. J. Vernon, R. E. Morrow, and D. J. Hoppe; "Design of a $\mathrm{TE}_{11}-\mathrm{HE}_{11}$ Mode Converter in a Highly Over-Moded Corrugated Circular Waveguide for ECRF Heating," American Physical Society Division of Plasma Physics Meeting in Boston, MA, October 29 November 2, 1984. 


\section{GRADUATE STUDENTS ASSOCIATED WTTH PAST AND PRESENT CONTRACT RESEARCH EFFORT}

The students listed below have, over the past years, performed the great majority of the work on this project.

Daniel J. Becker (Now with Texas Inst. in Dallas.)

Michael J. Buckley (Now with Westinghouse in Baltimore.)

* David Casper

Mark J. Heimbach (Now with Champion Technologies in Mlinois.)

Daniel J. Hoppe (Now at the Jet Propulsion Laboratory in California.)

Brian R. Johnson (Now with Westinghouse in Baltimore.)

Young-Hee Kim (Now with a company in Korea.)

* Jeffrey A. Lorbeck (Supported by a University Fellowship.)

Masoud Kasraian

* Gwo-Huei Luo

Richard E. Morrow (Now with Raytheon in Massachusetts.)

* Robb Peebles (Supported by a University Fellowship.)

William R. Pickles (Now with the Naval Research Laboratory in Washington)

Un Dong Rhee (Now in Dept. of Elect. Engr. of Korean Military Academy.)

Robert Schill (Now with the University of Ml. - Chicago.)

* Phillip J. Sealy

Fred Schleifer (Now with Plexus Technology Group in Neenah, Wis.)

* Jamal Shafii

David Stein (Now with McDonell-Douglas in St. Louis.)

* Currently with the project. 


\section{ACKNOWLEDGMENTS}

We would like to thank the following people for helpful discussions:

John Doane and Charles Moeller of General Atomics;

Kevin Felch, Hugo Huey, Howard Jory, and Jeff Neilson of Varian Associates;

T.V. George of the Department of Energy;

Jeff Casey, Ken Kreischer, and Richard Temkin of the MIT Plasma Fusion

Center;

Barry Stallard of Lawrence Livermore Laboratory; and

Manfred Thumm and Walter Kasparek of the Inst. for Plasma Research of the University of Stuttgart. 

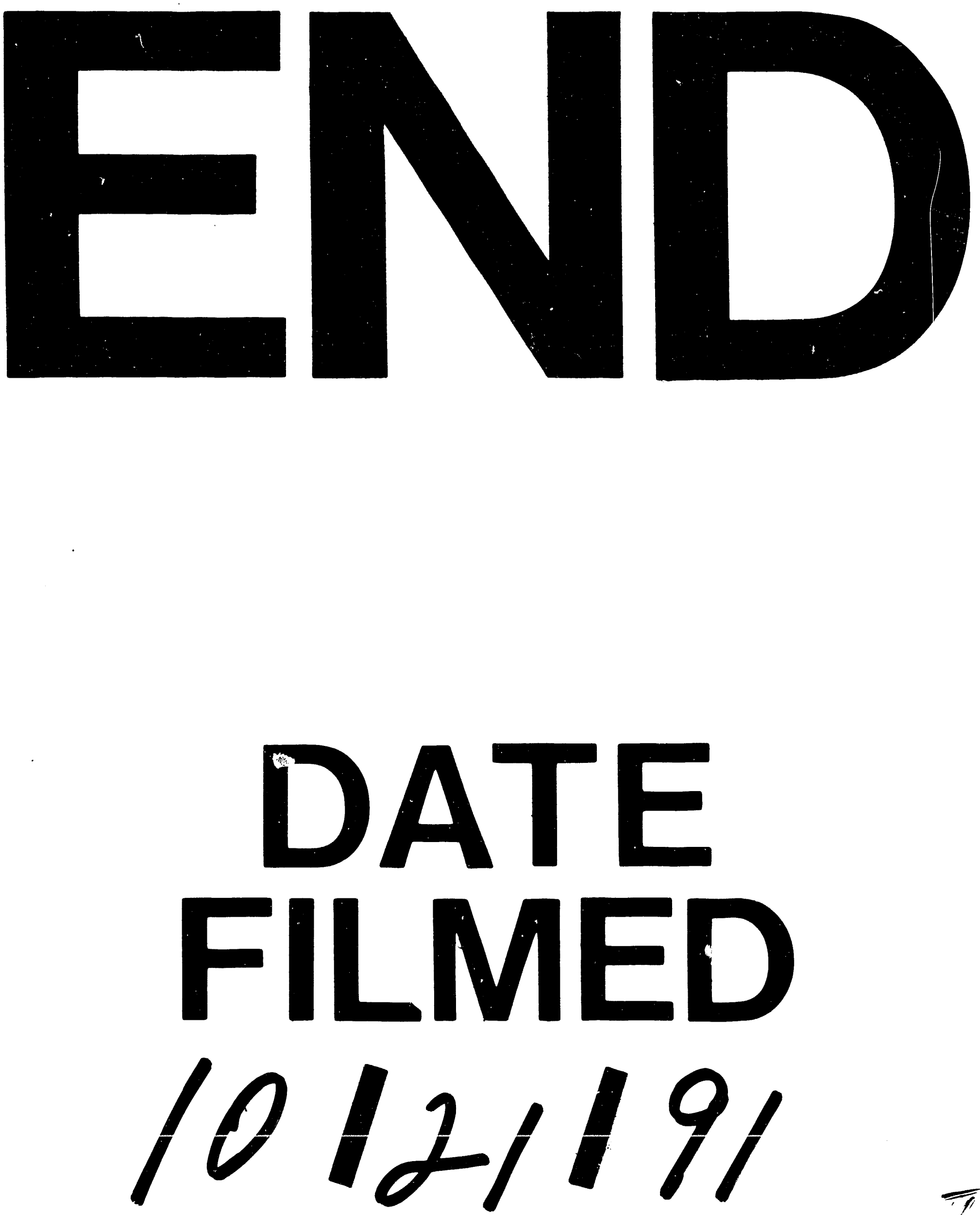
